Houcem Trabelsi, Enrique Romero, Mehrez Jamei

'Tensile strength during drying of remoulded and compacted clay: The role of fabric and water retention’ Applied Clay Science, Volume 162, 2018, Pages 57-68

https://doi.org/10.1016/j.clay.2018.05.032

(http://www.sciencedirect.com/science/article/pii/S0169131718302539)

\title{
Tensile strength during drying of remoulded and compacted clay: The role of fabric and water retention
}

\author{
Houcem Trabelsi ${ }^{\mathrm{a} *}$, Enrique Romero ${ }^{\mathrm{b}}$, Mehrez Jamei ${ }^{\mathrm{c}}$ \\ ${ }^{a}$ University of Tunis El Manar, National Engineering School of Tunis, Laboratory of Civil \\ Engineering, B.P.37, 1002, Belvedere, Tunis, Tunisia \\ ${ }^{\mathrm{b}}$ Department of Civil and Environmental Engineering, Universitat Politècnica de Catalunya, \\ Barcelona, Spain \\ c Northern Borders University, Engineering College, Saudi Arabia \\ *Corresponding author (houcem.trabelsi@enit.utm.tn)
}

\begin{abstract}
The paper presents an experimental investigation on the tensile strength of an unsaturated clay, both in remoulded and compacted states. To complete the experimental study, a new apparatus was designed with the purpose of determining direct tensile stress under controlled-displacement or controlled-force. The design exploits a direct shear test box, which was adapted to the scope of this investigation. Three different hydro-mechanical paths were followed before the tensile strength was determined: a) drying paths on remoulded samples; b) drying paths after compaction at different initial water contents; and c) dynamic compaction at different water contents, hence at different suctions and degrees of saturation. A microstructural investigation was also performed to better understand the experimental results and obtain the most relevant physical parameters. The preparation methods induced different initial fabrics, which dominated the water retention properties, as well as the tensile strength behaviour. A recent model for water retention, including the effects of multimodal fabric, was calibrated on available data and used to predict the suction of the samples along the drying paths, where direct information was not available. A simple model for tensile strength was proposed for its evolution, which included the role of multimodal fabric and their different water storage capabilities, the evolution of dry density and the initial water content (at the beginning of the tensile test path). For the compacted sample, typically showing a multimodal pore size distribution, the tensile strength was found to be a function of the state variables describing the macropore network. Dry density increases on drying
\end{abstract}


appeared in all the cases to dominate the tensile response, Water exchange and suction increase were well correlated to the tensile response evolution.

Keywords: tensile strength; remoulded clay; compacted clay; fabric; void ratio; water content

\section{Introduction}

Tensile strength of soils plays an important role in the initiation of cracks in drying soils, which strongly affects soil properties (increase in water permeability, decrease in stiffness and cohesion, to cite but a few of them). It is also accepted that tensile stress as a part of the effective stress has an important role in the stress-strain behaviour (Lu et al., 2007). Despite its importance, relatively few experimental works have been devoted to systematically investigate the tensile strength evolution under partially saturated conditions (see for instance, Nearing et al., 1991) especially in terms of the evolution of water content. For non-active clayey soils, some researchers have proposed to link the tensile strength to the degree of saturation or suction (Lu et al., 2005; Zeh and Witt, 2005; Ammeri, 2008; Stirling, 2014).

Besides, the tensile strength determination still remains as an important issue in unsaturated soil mechanics. The determination of its dependence on the unsaturated state, such as water content, void ratio, degree of saturation or suction, is often dependent on the testing method (indirect or direct testing devices). As shown by Barzegar et al. (1995), for a given initial state (dry density and water content), the tensile strength determination, not only depends on the way that it is measured, but also on the framework of the model used for the interpretation. Also, for some authors the tensile strength is well linked to the soil fabric. Therefore, tensile stress is considered isotropic when the packing particles arrangement is isotropic, and anisotropic in the opposite case. However, independently of such debate, which considers the tensile strength either as a macroscopic material property or as a micro-fabric stress depending on the particles arrangement and contacts, it has been established that the tensile strength is highly dependent on water content (Causarano, 1993; Kim and Hwang, 2003) and not only dependent on the degree of saturation (Lakshmikantha et al., 2012). Recently, Trabelsi et al. (2012) proposed a model to link the tensile stress and tensile strength to the porosity and suction as independent variables. The model has been used to simulate the desiccation tests. The present study particularly focuses on including these different issues (fabric effects, water content, suction, porosity, degree of saturation) to explain the tensile strength response of a compacted or remoulded clayey soil upon drying.

Evidently, the direct tensile stress device appears more appropriate, but the use of such apparatus is generally more adequate for compacted and stiff samples at low water contents (compacted dry 
of Proctor optimum). However, for remoulded soils or compacted samples at higher water contents, some experimental difficulties have been detected. For example, it is difficult to keep a homogeneous zone ('interest zone') for the application or measurement of the tensile stress. There is also the difficulty to measure the displacement in the 'interest zone', because of the low consistency of the wet samples. Compacting samples in the tensile stress apparatus is also a complicated issue, affecting the reproducibility of the results. Due to these difficulties, limited studies have been devoted to the tensile behaviour of unsaturated soils at high initial water contents. Most of the tensile test devices have been used for dried clayey soils (Frydman, 1964; Ammeri et al., 2009). Some experimental devices for tensile tests to capture lower tensile stress values have been designed (Nahlawi et al., 2004; Rodriguez et al., 2007).

To investigate and clarify these issues, the present paper presents different tensile strength tests that were performed on a new direct tensile device under controlled displacement and load on a clayey soil, following three different hydro-mechanical paths. Starting from a slurrystate, the remoulded clay was prepared in the direct tensile apparatus and subjected to progressive drying under controlled room conditions (relative humidity and temperature) before determining tensile strengths (this type of test will be hereafter referred as 'SD'). Tests were also performed on samples previously compacted at standard Proctor energy and then subjected to the same drying conditions (referred as 'CD' tests). Finally, other samples were compacted (standard Proctor energy) at specified water contents, and immediately submitted to tensile tests. These ascompacted tests are referred as 'C' tests. The laboratory tests were performed on clay samples from a region of Beja (in the north of Tunisia). In this soil formation, landslides have been frequently observed after intense development of cracks during drying and after wetting paths induced by rainfall.

To understand the tensile strength evolutions under the above-mentioned hydro-mechanical paths, pore size distribution analyses have been performed using mercury intrusion porosimetry tests. The link between the micro-structural evolutions along the different stress paths followed and the tensile strength-saturation state dependence (degree of saturation or suction) is analysed in the paper.

\section{Literature review: tensile strength and microstructural features}

Most of the work (Nearing et al., 1991; Lakshmikantha et al., 2012; Tang et al., 2014; Li et al., 2018; Stumpf et al., 2018) related to tensile strength has been conducted on compacted silty soils or on clayey soils with low plasticity, using a direct tensile apparatus under controlled force conditions. In this case, not only the difficulty of the lower consistency is not avoided, but also the post-peak tensile stress-displacement behaviour is not investigated. 
The experimental tests reported in the literature have been usually carried under constant void ratio at varying water contents. Test results show an important dependence of the tensile strength on suction (or current water content via the water retention curve) and on void ratio. Zeh and Witt (2007), who studied the tensile strength of medium plasticity clay, showed a much smaller increase in the tensile strength for suctions above $600 \mathrm{kPa}$ for dry side compacted materials compared to that obtained for samples prepared at the wet side. The authors explained this difference by the influence of soil fabric. They also showed that the increase in the tensile strength occurred up to a certain suction (around $10 \mathrm{MPa}$ ). Beyond this value, the tensile strength remained constant.

Lakshmikantha et al. (2012) showed a different trend of the tensile strength for compacted soils. Using a relative degree of saturation definition (effective degree of saturation as defined by Alonso et al., 2010), they obtained a tensile strength-effective degree of saturation evolution with a maximum strength at intermediate relative degrees of saturation (around 60\%). A similar behavioural picture has been reported in the literature for other compacted soils (Faveretti, 1995; Hagner, 2005; Tamarkar et al., 2007), in which tensile strength decreases with suction after reaching an intermediate maximum. This evolution of the tensile strength with degree of saturation is expected to be governed by microstructural features.

Microstructural features have gained increasing importance to improve understanding of phenomenological behavioural features of fine grained soils -compressibility, shear strength, water retention and water permeability-, as well as in setting out hypotheses for building up constitutive models (see for instance recent papers by Sanchez et al., 2005; Alonso et al., 2010; Kochmanová and Tanaka, 2011; Romero et al., 2011; Della Vecchia et al., 2013; Romero, 2013; Della et al., 2014; Divya et al., 2018). In this regard and if one considers the tensile strength to be associated with the capability of the porous media to sustain a given suction without appreciable desaturation, this strength should be also added to the aforementioned list since it is also related, besides water content and porosity, to soil microstructure -as given for instance by the pore size distribution-.

Most of these studies have been pertinent to compacted clayey soils due to their dominant multimodal pore size distribution created on preparation -particularly when they are prepared under dry conditions-. Nevertheless, the behaviour of remoulded soils with a single dominant pore mode is also importantly conditioned by its microstructure, despite not having been as thoroughly studied compared to compacted soils. In this regard, the present study does not only take into consideration both states of preparation (compacted samples at different water contents and remoulded samples), but also tries to explain the behavioural differences observed in tensile strength by considering microstructural features. 
Based on experimental data with mercury intrusion porosimetry, Romero et al. (2011) and more recently Della et al. (2014) have shown the important effects of the evolution of soil microstructure and porosity promoted mainly by drying and wetting paths and their consequences on the water retention properties -closely linked to the tensile strength of the soil-. These authors have shown important volume changes at intra-aggregation scale (pores inside soil aggregations) during these hydraulic paths. In the case of remoulded clayey soils, drying tends to progressively reduce the dominant pore size, which could be associated with the capability of the soil to sustain higher suctions without undergoing important desaturation -i.e., an increase in the air-entry value with the shrinking of the dominant pore size- and thus achieve higher tensile strengths. Zeh and Witt (2007) observed a monotonic increase with suction of the tensile strength of a compacted clayey soil undergoing drying and starting from high initial water content. In the case of compacted soils with multi-modal porosity features, the microstructural response on drying is more complicated due to the interaction between the different structural levels. For example, the progressive reduction of the pore volume at intra-aggregation scale during drying can induce inter-aggregate pore expansion (pores between soil aggregations), if the overall volume change of the soil is not greatly affected. The enlargement of this macropore volume has important consequences on the tensile strength since the compacted soil is no further capable of sustaining high suctions without undergoing desaturation (as observed by Lakshmikantha et al., 2012).

\section{Soil used in the investigation}

\section{Geotechnical properties and mineralogical composition}

The soil used in this study was Beja clay retrieved near a national Tunisian road, which was recently damaged after landslides triggered by rainfall (Jamei et al., 2015). Table 1summarises the geotechnical properties of the clay together with mineralogical composition and chemical analyses. According to consistency limits, the fine grained fraction classifies as high-plastic inorganic clay $(\mathrm{CH})$. The specific surface has been determined from mercury intrusion porosimetry data assuming cylindrical shape pores. The predominant clay minerals obtained from X-ray Diffraction (XRD) are Smectite (62\%) and Illite (22\%). Table 1 shows that the chemical characterisation of the soil constituents and LOI at $800^{\circ} \mathrm{C}$, which is essentially dominated by $\mathrm{SiO}_{2}$ and $\mathrm{CaO}$ oxides.

The air-dried soil was sieved through $75-\mu \mathrm{m}$ sieve and the passing material was the one used in the tests. Distilled water with an electrical conductivity of $2.7 \mu \mathrm{S} / \mathrm{cm}$ was used to prepare the samples. 
As previously indicated, three different states have been considered in the present study, namely dynamically compacted at standard Proctor energy (' $\mathrm{C}$ ' samples), dried to reach a target water content from a wetter compacted state ('CD' samples), and dried to reach specified water content starting from saturated (remoulded) state (this saturated state 'SD' has been prepared at initial water contents higher than the liquid limit reported in Table 1).

Table 1. Physical and chemical properties of Beja clay.

\begin{tabular}{|c|c|}
\hline Density of solids & $2.70 \mathrm{Mg} / \mathrm{m}^{3}$ \\
\hline Liquid limit (LL) & $62 \%$ \\
\hline Plastic limit (PL) & $30 \%$ \\
\hline Shrinkage limit (SL) & $15 \%$ \\
\hline Plasticity index (IP) & $32 \%$ \\
\hline Fraction $<75 \mu \mathrm{m}$ & $90 \%$ \\
\hline Finer fraction $(<2 \mu \mathrm{m})$ & $33 \%$ \\
\hline $\begin{array}{l}\text { Water content under hygroscopic conditions (relative humidity: } \\
50 \% \text { ) }\end{array}$ & $4.3 \%$ \\
\hline Specific surface (mercury intrusion porosimetry) & $24 \mathrm{~m}^{2} / \mathrm{g}$ \\
\hline Soil organic content & $0.72 \%$ \\
\hline Calcium carbonate content (AFNOR NF X31-106) & $36.8 \%$ \\
\hline Value of methylene blue (AFNOR NF P94-068) & $8.3 \mathrm{~g} / 100 \mathrm{~g}$ \\
\hline \multicolumn{2}{|l|}{ Bulk-rock mineralogy } \\
\hline Calcite & $73 \%$ \\
\hline Quartz & $17 \%$ \\
\hline ACM & $10 \%$ \\
\hline \multicolumn{2}{|l|}{ All clay minerals (basing on XRD tests) } \\
\hline Smectite & $85 \%$ \\
\hline Illite & $13 \%$ \\
\hline Kaolinite & $2 \%$ \\
\hline \multicolumn{2}{|l|}{ Chemical constituents and LOI at $1000^{\circ} \mathrm{C}$} \\
\hline $\mathrm{SiO}_{2}$ & $22.43 \%$ \\
\hline $\mathrm{CaO}$ & $33.64 \%$ \\
\hline $\mathrm{Al}_{2} \mathrm{O}_{3}$ & $8.71 \%$ \\
\hline $\mathrm{Fe}_{2} \mathrm{O}_{3}$ & $2.01 \%$ \\
\hline $\mathrm{K}_{2} \mathrm{O}$ & $1.09 \%$ \\
\hline $\mathrm{TiO}_{2}$ & $0.58 \%$ \\
\hline $\mathrm{Na}_{2} \mathrm{O}$ & $1.47 \%$ \\
\hline $\mathrm{MgO}$ & $1.51 \%$ \\
\hline LOI & $28.56 \%$ \\
\hline
\end{tabular}

\section{Microstructural description of some tested samples}

Mercury intrusion porosimetry (MIP) tests on freeze-dried samples have been performed to study the pore size distribution of some samples prepared at given states. The technique has limitations associated with the range of entrance pore sizes that can be measured (Romero and Simms, 2008): 
a) pore sizes $>450 \mu \mathrm{m}$ cannot be detected, which defines the non-detected porosity; and b) pore sizes lower than $7 \mathrm{~nm}$ cannot be intruded (associated with the non-intruded porosity). MIP tests on saturated samples have been prepared at two water contents (water content $w=46.5 \%$ and void ratio $e=1.25$; and $w=24.0 \%$ and $e=0.648$ ). A third and fourth test was carried out on dried material $(w=4.6 \%$ and $e=0.440 ; \quad$ and $w=3.2 \%$ and $e=0.410)$ starting from saturated (remoulded) state, and a fifth one performed on dynamically compacted sample at $w=24.4 \%$ and $e=1.08$. The cumulative intruded void ratio $e_{n w}$ (intruded volume over solid volume) along intrusion and extrusion paths for both 'SD' and as-compacted 'C' samples are presented in Fig. 1. The non-intruded void ratio was estimated using data of the air-dried sample starting from saturation, which could shrink freely without crack formation -thus ensuring nil non-detected void ratio-. Consistent results have been measured on 'SD' samples, in which an average nonintruded void ratio of 0.11 has been considered. Assuming that the non-intruded void ratio is the same for the compacted 'C' sample, the non-detected void was estimated as 0.326 (Fig. 1). Fig. 2 presents the pore size density function PSD plots for the four states. It can be observed that 'SD' samples display mono-modal PSD curves that besides reducing in area (intruded void ratio) they undergo a consistent shift towards lower dominant pore sizes at decreasing water contents. On the contrary, the compacted sample shows at least two dominant pore modes $(40 \mu \mathrm{m}$ for the macropores, and $0.1 \mu \mathrm{m}$ for the micropores), in which the presence of large inter-aggregate pores indicates the open structure created during dry-side compaction at $e=1.08$. As observed in Fig. 2, a pore size of $2 \mu \mathrm{m}$ has been selected to separate micropores and macropores. The separation of these two domains follows the criterion described in Romero et al. (2011), corresponding to the peak of the mono-modal PSD and the valley of the bi-modal PSD. This separation allows determining the volume of micropores (area under the PSD curves for pores sizes below $2 \mu \mathrm{m}$ ).

Fig. 3 presents the shrinkage curve and the consistency limits, in which the desaturation under unstressed conditions leads to a linear trend between void ratio and water content. The void ratio stabilises when the water content reaches the shrinkage limit, which is around $w_{S L}=15 \%$. 


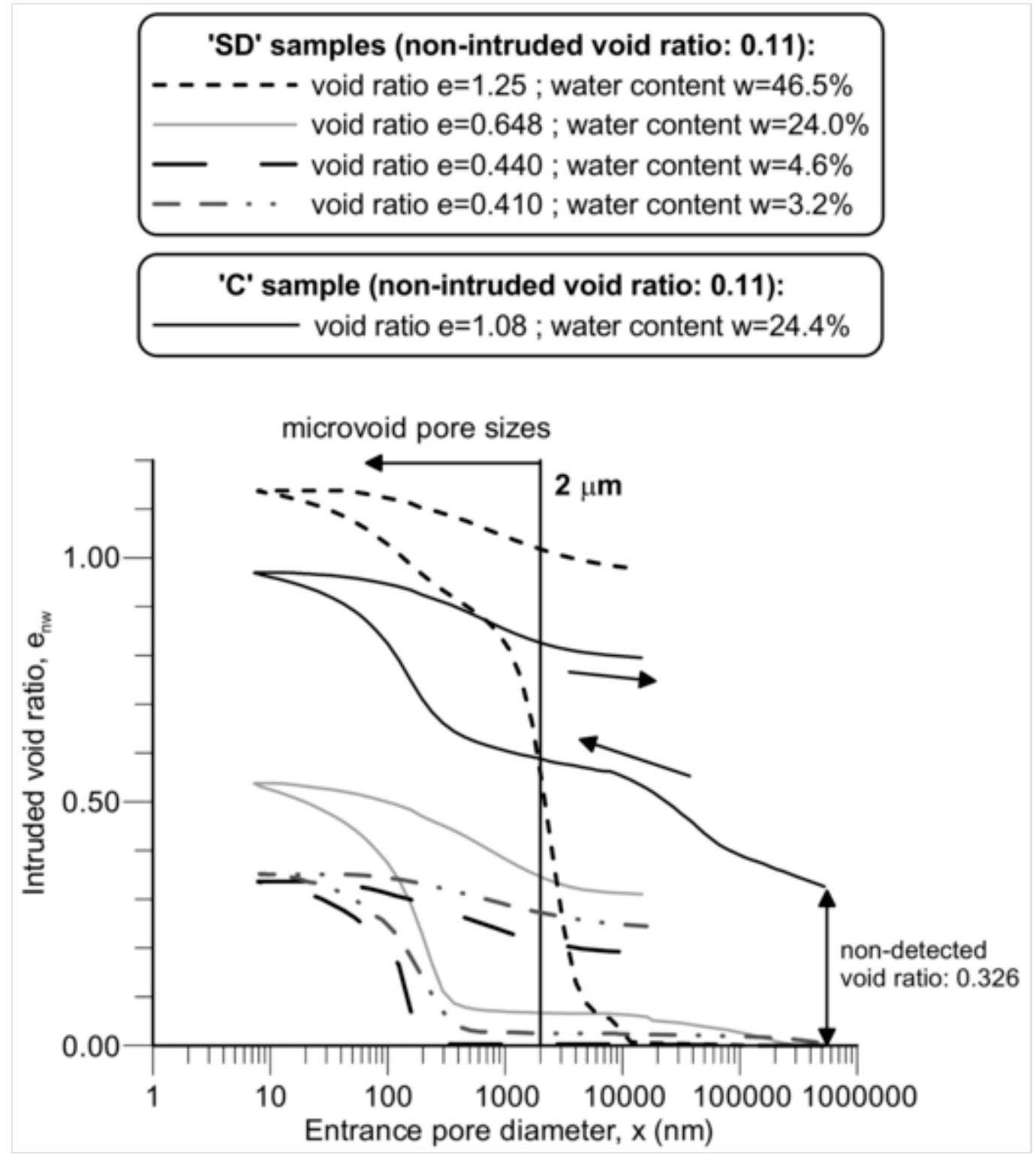

Fig. 1 Cumulative intruded void ratio (intrusion-extrusion path). Remoulded and dried samples 'SD' and as-compacted sample 'C'. 


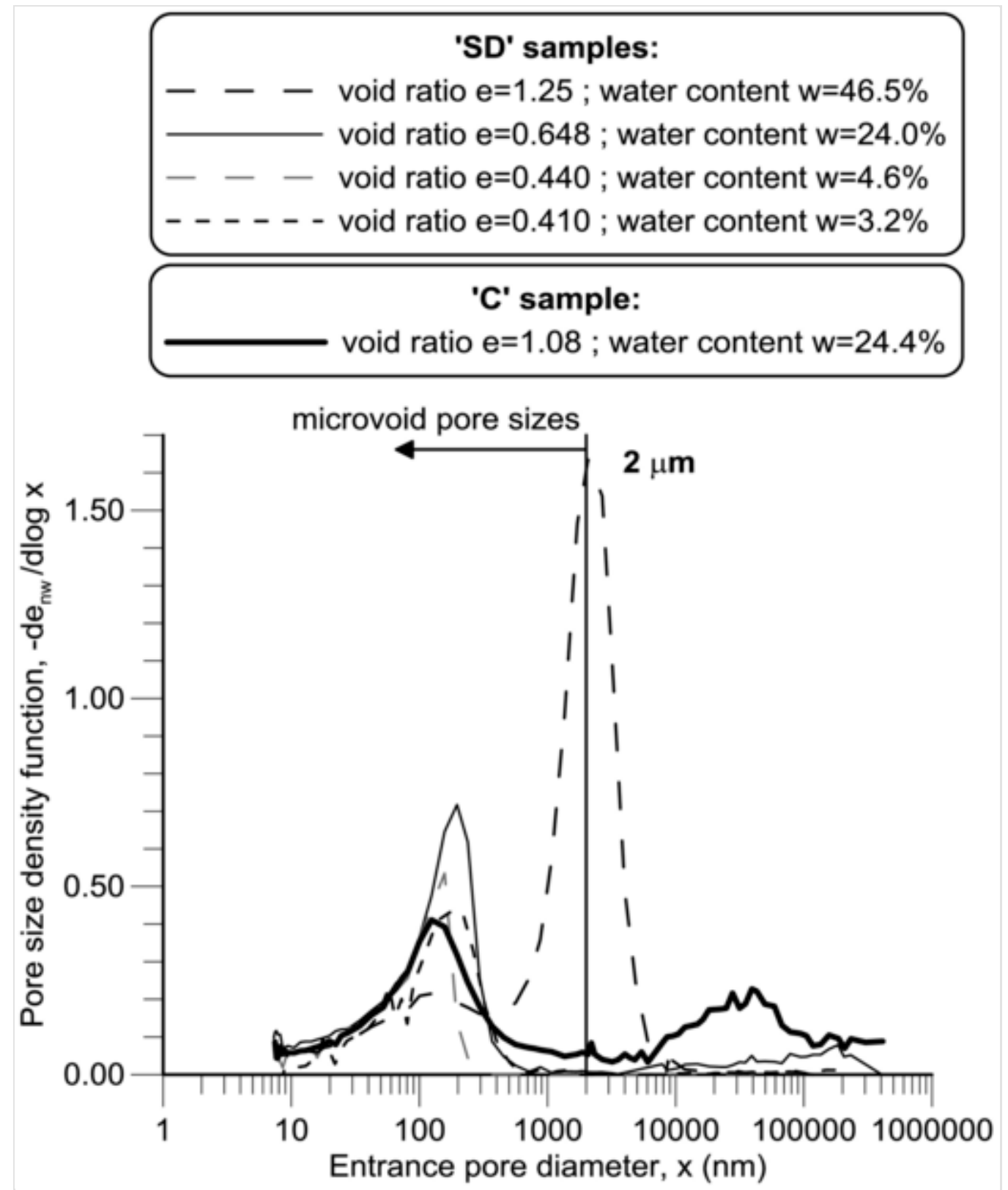

Fig. 2 Pore size density functions. Remoulded and dried samples 'SD' and as-compacted sample ' $C$ '. 


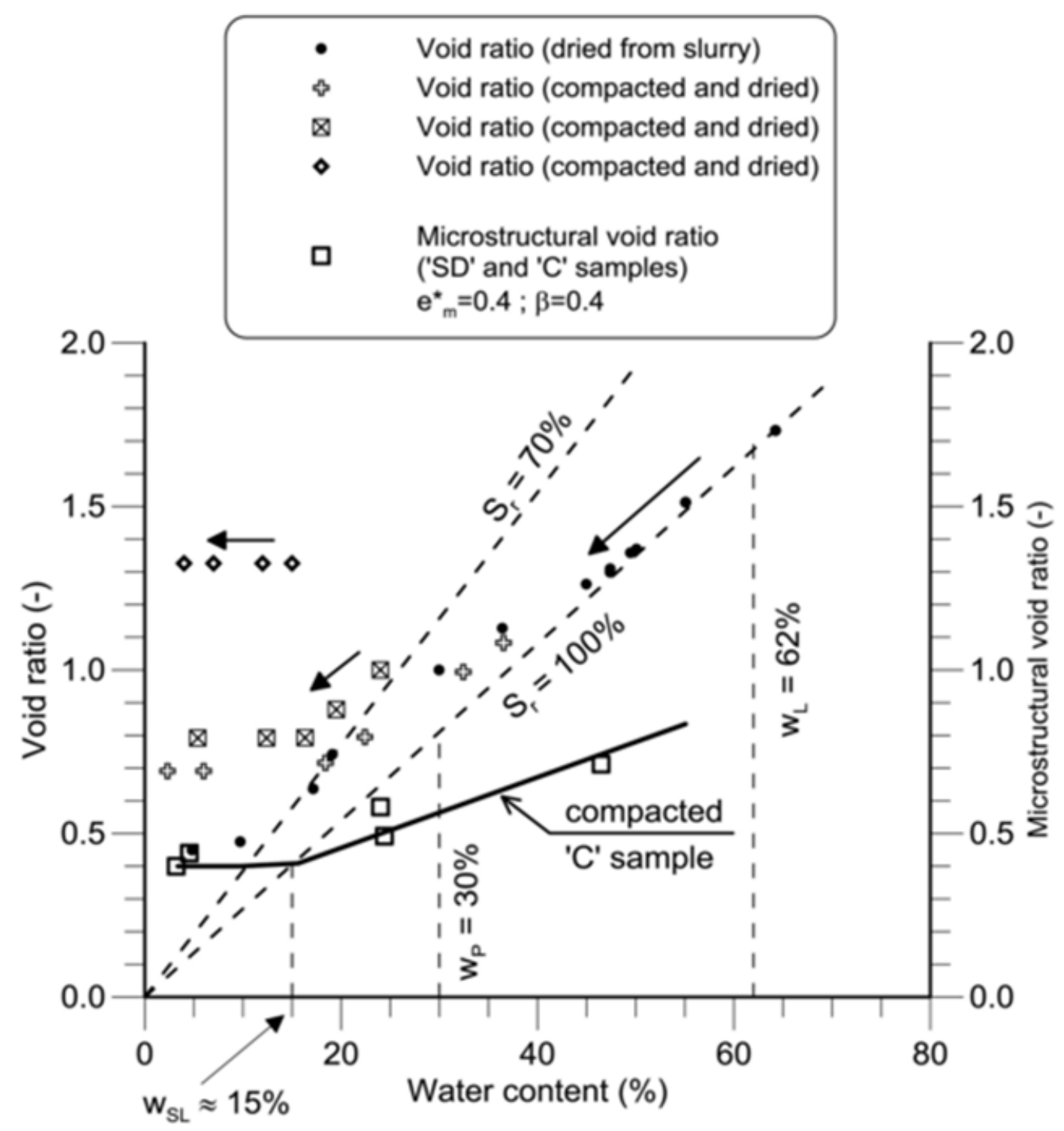

Fig. 3 Shrinkage curves in terms of void ratio (dried from slurry, and compacted and dried) and microstructural void ratio ('SD' and 'C' samples).

The equation proposed by Romero et al. (2011) has been used to fit the evolution of the microstructural void ratio $e_{m}$ against the water content $w$. The microstructural void ratio has been determined from the PSD curves presented in Fig. 2 and represents the volume of pores over volume of solids for pore sizes below $2 \mu \mathrm{m}$ that are assumed inside aggregates.

$e_{m}=e_{m}^{*}+\beta\left\langle e_{w}-e_{m}^{*}\right\rangle=e_{m}^{*}+\beta \frac{\rho_{S}}{\rho_{w}}\left\langle w-w_{S L}\right\rangle$

where $\langle x\rangle=x$ if $x \geq 0$ and $\langle x\rangle=0$ if $x \leq 0 ; e_{w}=\rho_{s} w / \rho_{w}$ is the water ratio (water volume over volume of solids) with $\rho_{s}$ and $\rho_{w}$ the density of solids and water, respectively $\left(\rho_{s} / \rho_{w}=2.70\right) ; \boldsymbol{e}_{m}^{*}$ 
$=\rho_{s} w_{S L} / \rho_{w}=0.40$ is the shrinkage limit expressed as water ratio; and $\beta=0.40$ is the slope of the linear part of the microstructural shrinkage curve (see Fig. 3).

Water retention properties: modelling the evolution of microstructure and void ratio dependence

Fig. 4 shows the water retention curve in terms of water content. It includes the evolution of void ratio, which has an important effect on water retention behaviour and allows determining the degree of saturation. The water retention curve shown in Fig. 4 was determined following a drying path under unstressed conditions and starting from remoulded state (initial void ratio around $e=1.75$ ). A final void ratio $e f=0.44$ was finally achieved after air-drying at a relative humidity of 50\% (total suction around $100 \mathrm{MPa}$ ). Several techniques were used to cover a wide suction range, namely mid-range tensiometer for matric suctions lower than $200 \mathrm{kPa}$ (T5x, UMS, Germany) and dew point mirror psychrometer (WP4, Decagon Devices Inc., USA). As shown in the figure, the different techniques display consistent results and present no important void ratio effects at suctions higher than $5 \mathrm{MPa}$ as also indicated by Romero et al. (2011). Fig. 4 also shows the effect of the different sample preparations (slurry-drying path 'SD' and compacted states 'C'). Fig. 5 presents the water retention information on drying 'SD' and for the compacted states ' $C$ ' in terms of degree of saturation. An important effect of void ratio is still observed when using degree of saturation. This strong dependence of water retention on void ratio should be therefore included for correctly assessing the tensile strength properties. 


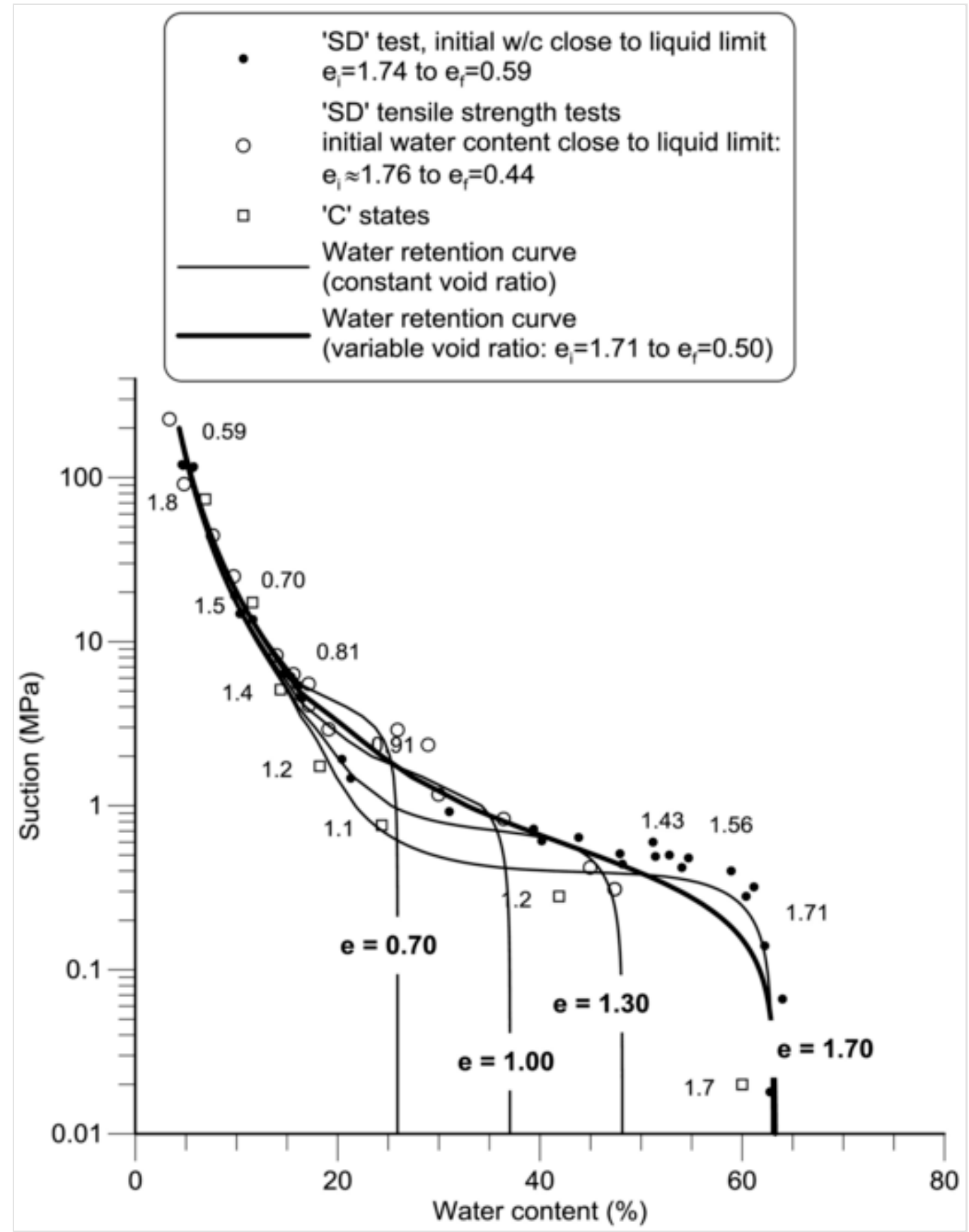

Fig. 4 Water retention curves in terms of water content starting from remoulded conditions ('SD' paths) and 'C' states. Model simulations at different void ratios. 


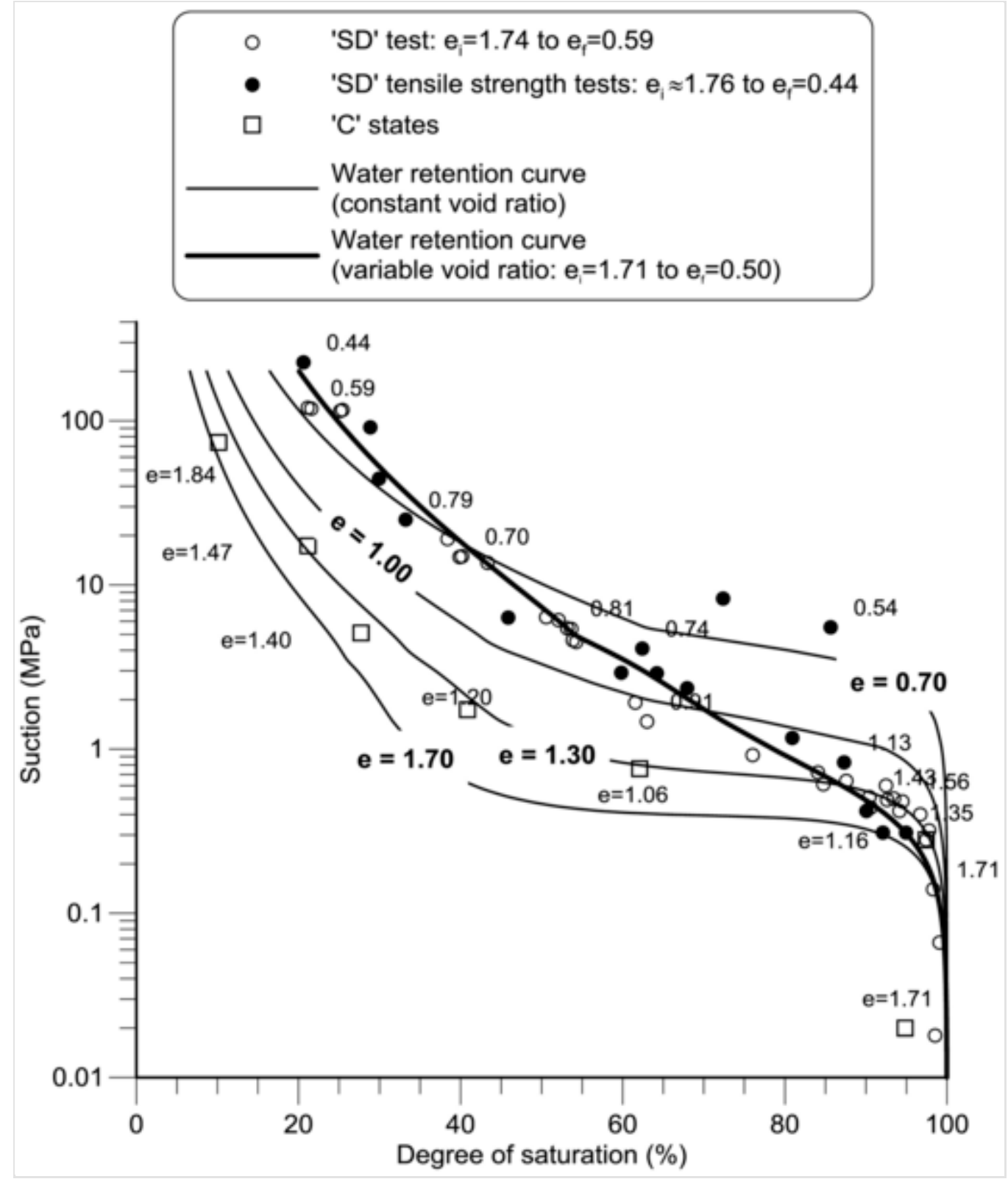

Fig. 5 Water retention curves in terms of degree of saturation starting from remoulded conditions ('SD' paths) and 'C' states. Model simulations at different void ratios.

Della et al. (2014) proposed a model to predict the water content for different dry densities under different hydro-mechanical paths and using information of the pore size distribution. Indeed, the retention mechanism is described by two structural levels associated with the inter-aggregate pores (macropores) and intra-aggregate pores (micropores). The water retention model is expressed as follows (Eq. (2)): 
$e_{w}=\frac{\rho_{s}}{\rho_{w}} w=\left(e-e_{m}\right)\left[1+\left(\frac{s}{s_{0}{ }^{M}}\right)^{n^{M}}\right]^{-m^{M}}+e_{m}\left[1+\left(\frac{s}{s_{0}{ }^{m}}\right)^{n^{m}}\right]^{-m^{m}}$

where $w$ is the water content, $e_{M}$ and $e_{m}$ are respectively the macrostructural and microstructural void ratios $\left(e_{M}=e-e_{m}\right), e$ is the total void ratio, $n$ and $m$ are van Genuchten's parameters defined for the macro and microstructural domains (using the symbols $(M)$ and $(m)$, respectively). And finally, the parameter $s_{0}$ is close to the air-entry suction value, also defined separately for the macro and microstructural pores, or inter-aggregate and intra-aggregate pores (see Romero et al., 2011).

The parameters s0m and s0M are assumed to evolve exponentially (in the considered range of values) respectively with the microstructural void ratio em and with the ratio e-eme. The following equations were proposed by Della et al. (2014):

$$
\begin{aligned}
& s_{0}{ }^{m}=\alpha_{1}{ }^{m} \exp \left(-\alpha_{2}{ }^{m} e_{m}\right) \\
& s_{0}{ }^{M}=\alpha_{1}{ }^{M} \exp \left(-\alpha_{2}{ }^{M} \frac{e-e_{m}}{e}\right)
\end{aligned}
$$

The water retention results have been fitted to the previous equations and model parameters are summarised in Table 2. The model results are presented in Figs. 4 and 5. The model consistently captures the main features of the experimental results. Particularly indicating no important void ratio effects at suctions higher than $5 \mathrm{MPa}$ when plotted in terms of water content (Fig. 4) and the systematic increase of the air-entry suction with the decrease of void ratio (Figs. 4 and 5).

Table 2. Parameters used in the water retention (Eqs. (1) to (4)) and tensile strength models.

\begin{tabular}{llll}
\hline Scale & \multicolumn{2}{l}{ Water retention Eqs. (1) to (4) } \\
\hline \multirow{2}{*}{ Microstructural } & $\alpha_{1}{ }^{m}$ & MPa & 3.94 \\
& $\alpha_{2}{ }^{m}$ & - & 0.12 \\
$n^{m}$ & - & 3.65 \\
$m^{m}$ & - & 0.094 \\
& $e_{m}{ }^{m}$ & - & 0.4 \\
$\beta$ & $\beta$ & - & 0.4 \\
Macrostructural & $\alpha_{1}{ }^{M}$ & MPa & 37.66 \\
& $\alpha_{2}{ }^{M}$ & - & 10 \\
& $n^{M}$ & - & 1.79 \\
& $m^{M}$ & - & 0.44 \\
\hline
\end{tabular}




\section{Equipment and methodology: direct tensile apparatus and paths followed}

The testing program for the present study involved direct tensile tests under controlled force and displacement conditions. A direct tensile apparatus similar to that used by Lakshmikantha et al. (2012) and originally developed by Mikulitsch and Gudehus (1995), was used to perform the controlled-force tests.

A new direct tensile apparatus under controlled displacement conditions have been recently designed, particularly adapted to be placed in a conventional direct shear box. Fig. 6 shows a photograph of the new cell placed in the direct shear box, which presents approximately the same shape of the previously described cell (two trapezoidal shape pieces at both extremes and a central part). As shown in the figure, the central part ('zone of interest') has a length and width of $20 \mathrm{~mm}$. One extreme is fixed to the moving box and the other one is connected to a $1 \mathrm{kN}$ range load cell. The rate of displacement used to perform these tests was $0.1 \mathrm{~mm} / \mathrm{min}$. During the tensile tests, the displacement was measured with an LVDT transducer and the tensile force automatically recorded from the load cell output.

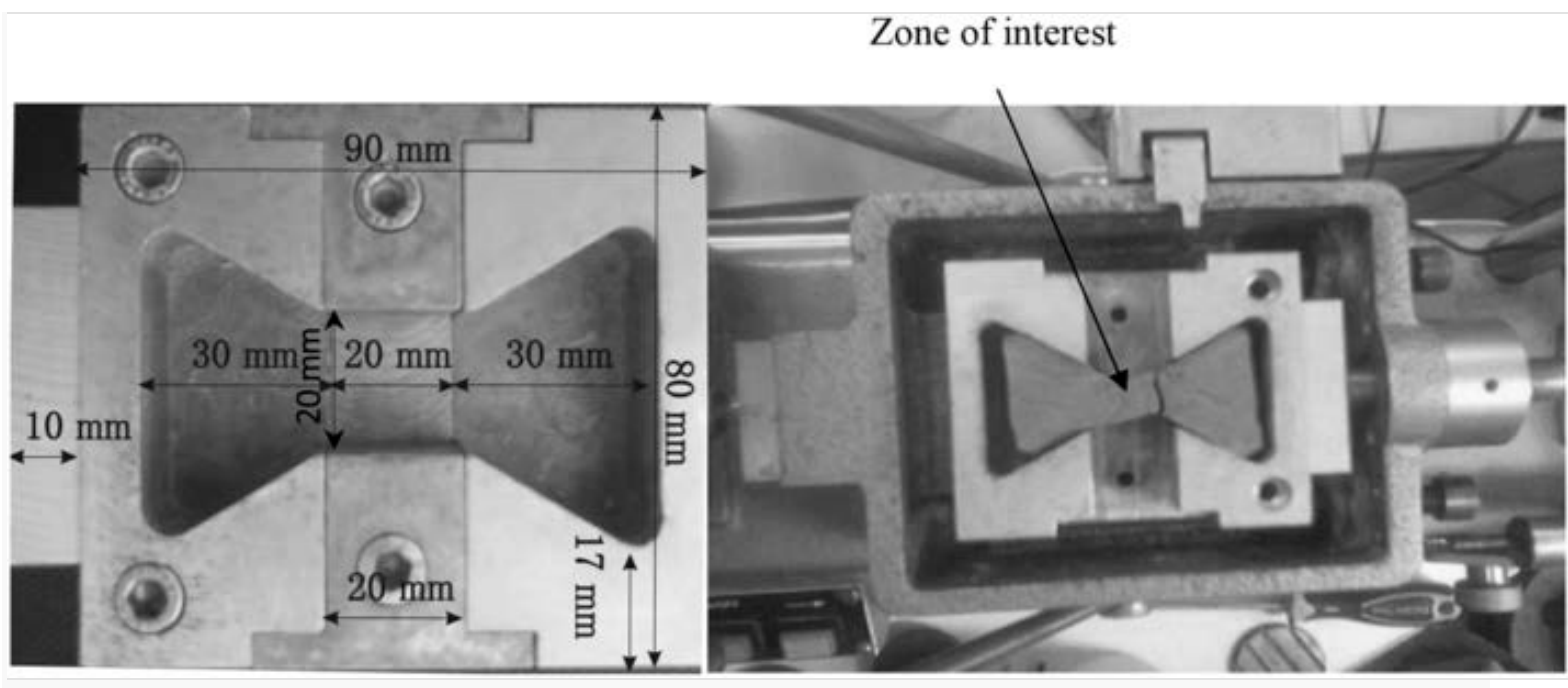

Fig. 6 Tensile test apparatus under controlled-displacement conditions installed inside a direct shear box.

At the end of each tensile test, the suction was measured by a mid-range tensiometer and a dew point mirror psychrometer. The final water contents were also determined. These tests were performed on samples retrieved from the 'zone of interest'. It is important to highlight that the direct tensile test under controlled displacement has been proposed to better define the post-peak response. As previously indicated, three series of tests were performed for remoulded and dried samples ('SD' test series at controlled load and displacement), as well as for compacted states at standard Proctor energy (' $\mathrm{C}$ ' test series at controlled displacement) and for compacted and then dried samples ('CD' test series at controlled displacement). Samples for tests 'SD' and 'CD' are 
subjected to controlled air-drying before performing tensile tests at specified water contents. Fig. 7 shows the stress paths followed (in terms of dry density and water content) plotted in the compaction diagram. Table 3a summarises the initial water content and the soil state (water content, void ratio, degree of saturation and suction) at tensile strength conditions corresponding to the controlled load 'SD' tests. Table 3b presents the soil state at the tensile strength tests ' $\mathrm{C}$ ' and 'SD' using controlled displacement conditions. Table 3c summarises the soil state at the tensile strength of tests 'CD1', 'CD2' and 'CD3' using controlled-displacement conditions.

\section{Experimental results on tensile stress}

Fig. 8 presents the evolution of the tensile stress of the slurry and dried 'SD' samples along the different displacement-controlled tests. During drying, samples underwent shrinkage and gaps resulted between sample and rigid moulds. The curves present the tensile stress evolution once a good contact was ensured. After reaching maximum tensile strength (at displacements around $0.11 \mathrm{~mm}$ to $0.27 \mathrm{~mm}$ ), the brittle and driest samples (water contents below $w=15.63 \%$ ) underwent a very sharp drop of stress. Fig. 9 shows the corresponding evolutions of the compacted ' $\mathrm{C}$ ' materials along the displacement-controlled tests. These curves presented much lower maximum tensile strengths, in which peaks and a smoother post-peak decay were observed at the lower water contents (below 24.36\%) and at displacements between $0.08 \mathrm{~mm}$ and $0.42 \mathrm{~mm}$ (except for test with sample at $w=6.91 \%$ ). Test results on 'C' samples displayed maximum tensile strengths at water contents between $11.57 \%$ and $18.23 \%$ (below the optimum standard Proctor water content of around 32\%). 


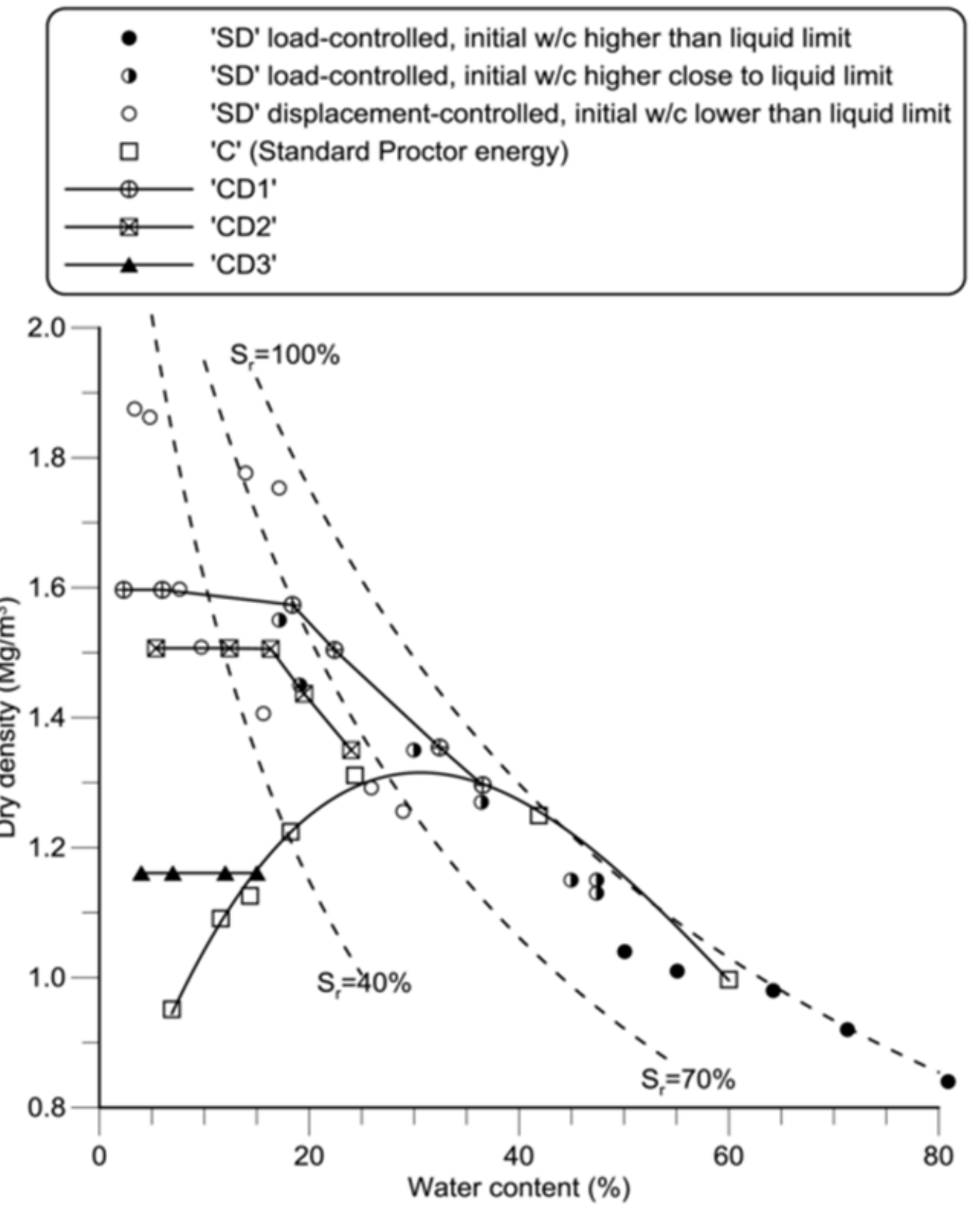

Fig. 7 Stress paths followed (in terms of dry density and water content) plotted in the compaction diagram. Test series on slurry and then dried samples ('SD'), test series on compacted ' $C$ ' states (standard Proctor test energy) and test series on compacted and dried samples ('CD'). 
Table 3a. Soil conditions at tensile strength. Controlled load tests. 'SD’ paths.

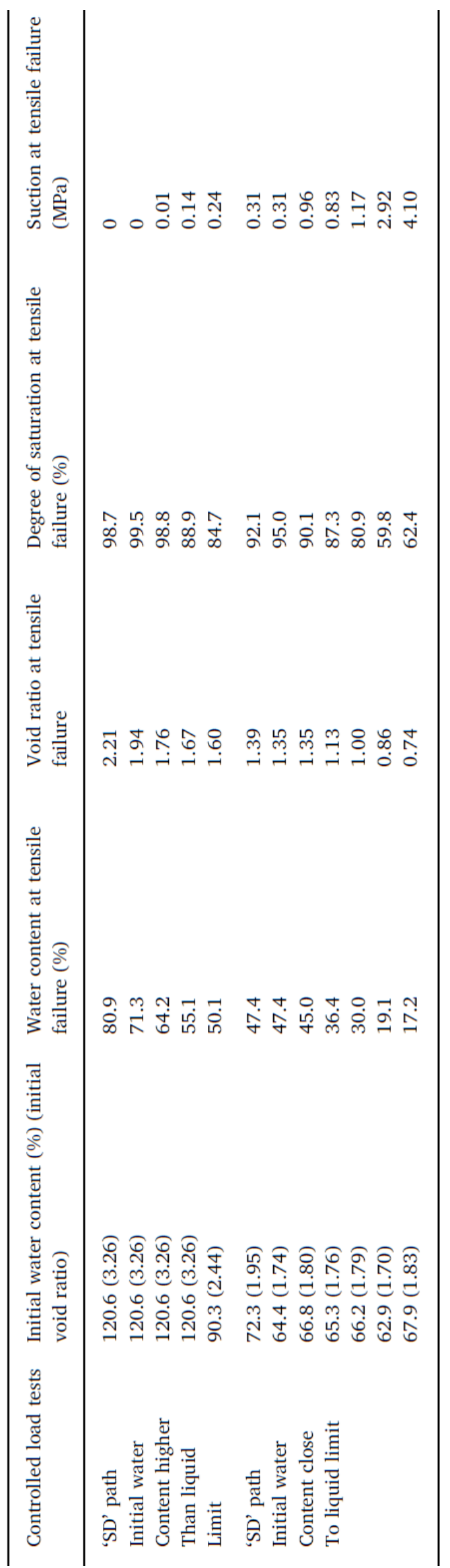


Table 3b. Soil conditions at tensile strength. Controlled displacement tests. 'C' states and 'SD' paths.

\begin{tabular}{lllll}
\hline $\begin{array}{l}\text { Controlled } \\
\text { displacement tests }\end{array}$ & $\begin{array}{l}\text { Water } \\
\text { content at } \\
\text { tensile } \\
\text { failure (\%) }\end{array}$ & $\begin{array}{l}\text { Void ratio } \\
\text { at tensile } \\
\text { failure }\end{array}$ & $\begin{array}{l}\text { Degree of } \\
\text { saturation at } \\
\text { tensile failure } \\
(\%)\end{array}$ & $\begin{array}{l}\text { Suction at } \\
\text { tensile } \\
\text { failure } \\
\text { (MPa) }\end{array}$ \\
\hline 'C' state & 60.0 & 1.71 & 94.8 & 0.02 \\
& 41.9 & 1.16 & 97.4 & 0.28 \\
& 24.4 & 1.06 & 62.1 & 0.76 \\
& 18.2 & 1.21 & 40.9 & 1.74 \\
'SD' path & 14.4 & 1.40 & 27.7 & 5.10 \\
Initial water & 11.6 & 1.48 & 21.2 & 17.3 \\
Content higher & 6.9 & 1.84 & 10.2 & 73.8 \\
Than liquid & 28.9 & 1.15 & 68.0 & 2.35 \\
Limit & 17.1 & 1.09 & 64.2 & 2.90 \\
& 15.6 & 0.54 & 85.7 & 5.52 \\
& 13.9 & 0.92 & 45.9 & 6.33 \\
& 9.7 & 0.52 & 72.4 & 8.26 \\
& 7.7 & 0.79 & 33.2 & 25.0 \\
& 4.8 & 0.69 & 29.9 & 94.4 \\
& 3.4 & 0.45 & 28.9 & 227 \\
\hline
\end{tabular}


Table 3c. Soil conditions at tensile strength. Controlled displacement tests. 'CD1', 'CD2' and ‘CD3’ paths.

\begin{tabular}{lllll}
\hline $\begin{array}{l}\text { Controlled } \\
\text { displacement tests }\end{array}$ & $\begin{array}{l}\text { Water } \\
\text { content at } \\
\text { tensile } \\
\text { failure (\%) }\end{array}$ & $\begin{array}{l}\text { Void ratio } \\
\text { at tensile } \\
\text { failure }\end{array}$ & $\begin{array}{l}\text { Degree of } \\
\text { saturation at } \\
\text { tensile failure } \\
(\%)\end{array}$ & $\begin{array}{l}\text { Suction at } \\
\text { tensile } \\
\text { failure } \\
\text { (MPa) }\end{array}$ \\
\hline 'CD1' path & 36.5 & 1.08 & 91.1 & 0.73 \\
& 32.4 & 0.99 & 88.1 & 1.89 \\
& 22.4 & 0.80 & 76.1 & 2.45 \\
& 18.4 & 0.72 & 69.4 & 12.8 \\
& 6.0 & 0.69 & 23.4 & 43.8 \\
'CD2' path & 2.3 & 0.69 & 9.1 & 242 \\
& 24.0 & 1.00 & 64.8 & 0.76 \\
& 19.5 & 0.88 & 59.9 & 1.92 \\
& 16.3 & 0.80 & 55.6 & 3.21 \\
& 12.4 & 0.79 & 42.3 & 8.36 \\
& 5.4 & 0.79 & 18.4 & 178 \\
& 15.0 & 1.33 & 30.5 & 12.5 \\
& 12.0 & 1.33 & 24.4 & 52.6 \\
& 7.0 & 1.33 & 14.3 & 152 \\
\hline
\end{tabular}




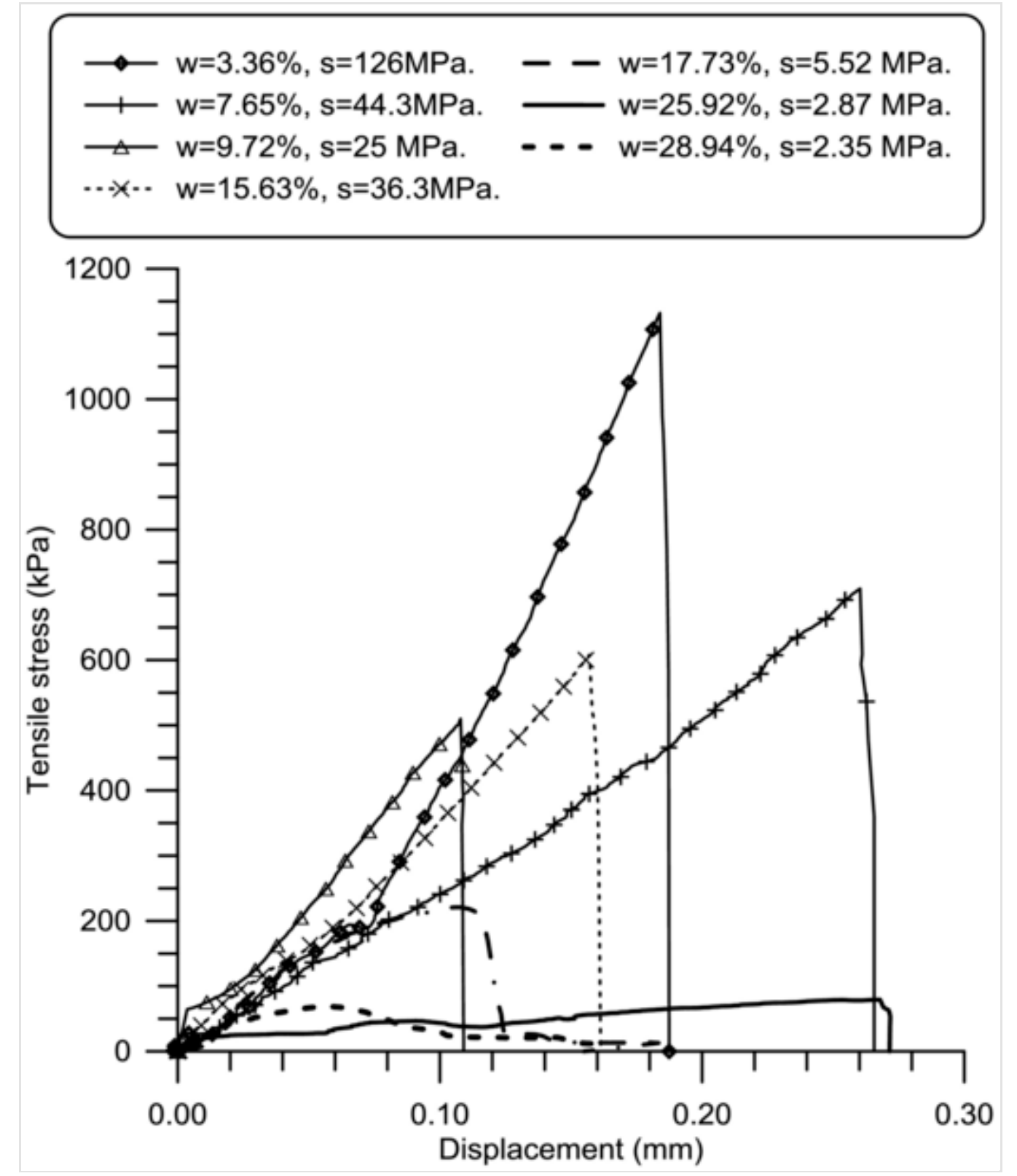

Fig. 8 Tensile stress evolution for remoulded and dried clay (path 'SD') carried out under controlled-displacement conditions. 


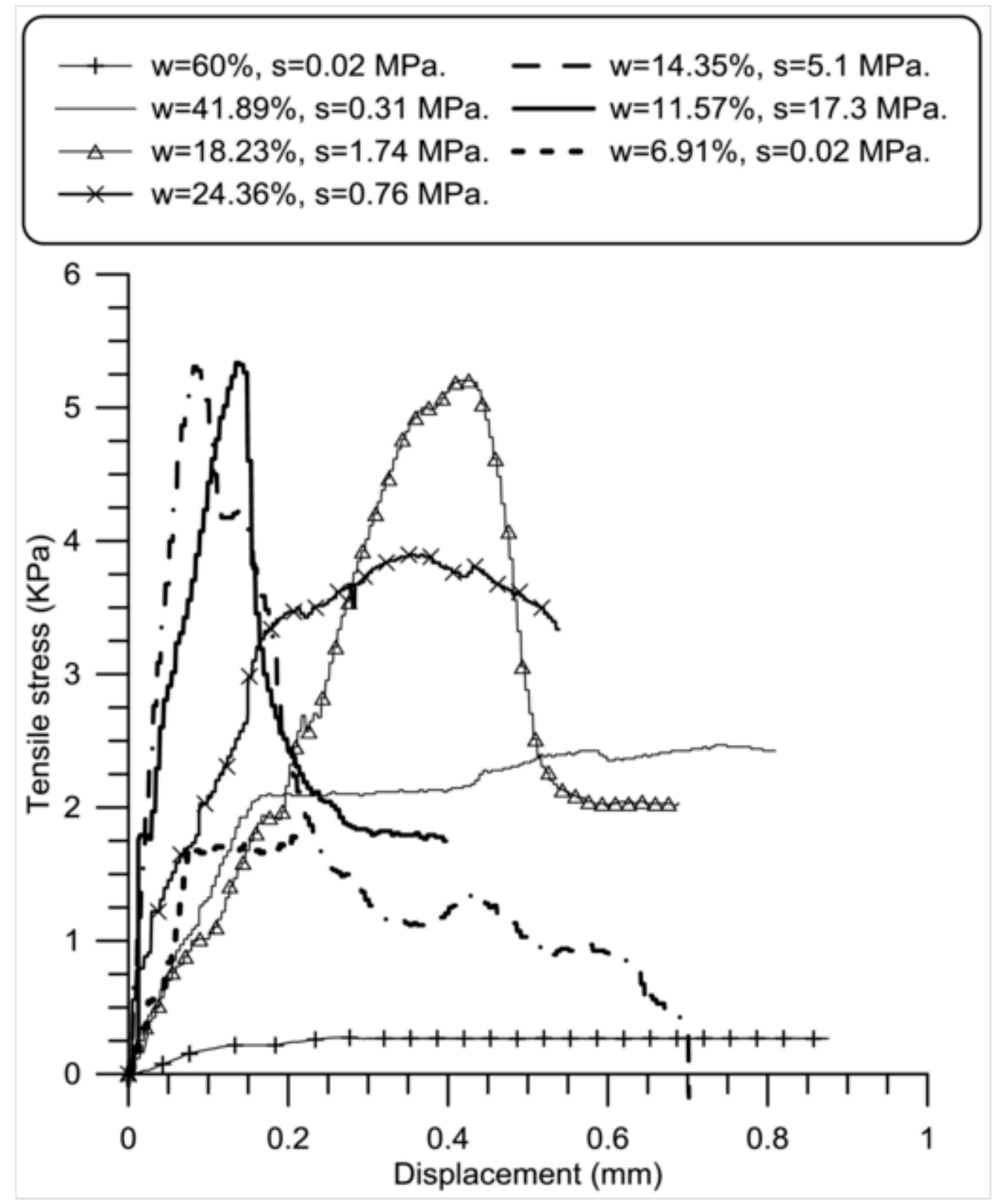

Fig. 9 Tensile stress evolution on as-compacted clay (states 'C') carried out under controlleddisplacement conditions.

Fig. 10 summarises the displacement-controlled results in terms of tensile strength water content relationship for the different tests ('SD' and 'CD' paths, and 'C' states), in which void ratios are indicated as labels. Stress-controlled results of 'SD' samples are also included starting from two different initial water contents (higher and close to liquid limit). When comparing drying results, and regardless the initial preparation method (compacted states or slurry), it seems that logarithm tensile strength results on drying tend to align parallel and to be positioned according to the initial moisture content of the material. The role of this initial fabrication water content will be later discussed. 


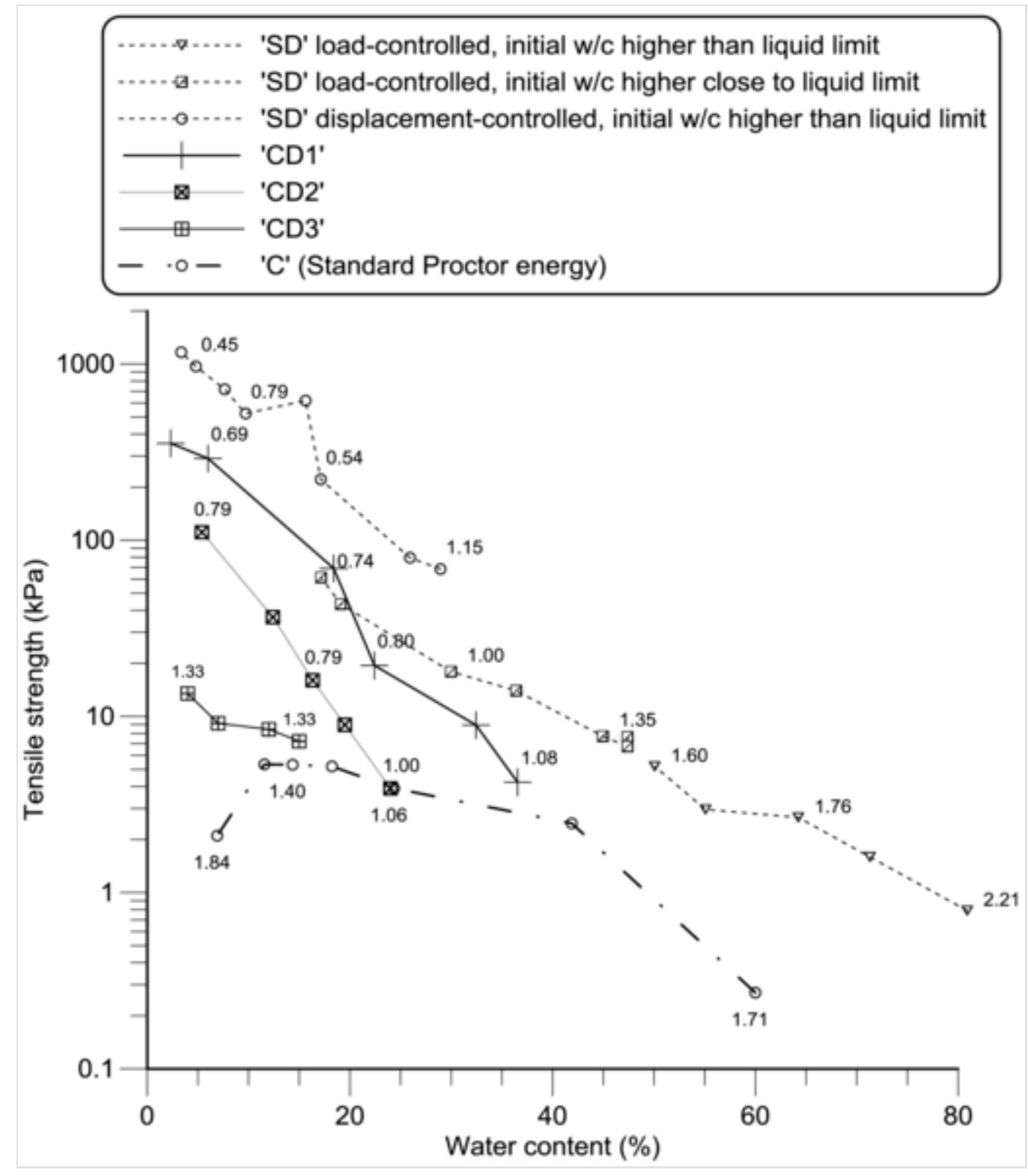

Fig. 10 Tensile strength as a function of water content for remoulded/dried ('SD'), ascompacted ('C') states and compacted/dried ('CD') paths. Void ratios are indicated by labels.

Fig. 11 displays the same information but plotted against degree of saturation, in which void ratios are indicated as labels. Test results on ' $\mathrm{C}$ ' samples show that maximum tensile strengths are attained at degrees of saturation between $21 \%$ and $41 \%$, and lower than optimum conditions. Previous studies carried out on as-compacted silty soils (see for instance, Lakshmikantha et al., 2012) also showed a maximum tensile strength at degrees of saturation around $60 \%$ (below optimum conditions). In 'SD' samples, drying tends to progressively reduce void ratio, which is 
associated with a better capability of the soil to sustain higher suctions without undergoing important desaturation and thus achieve higher tensile strengths.

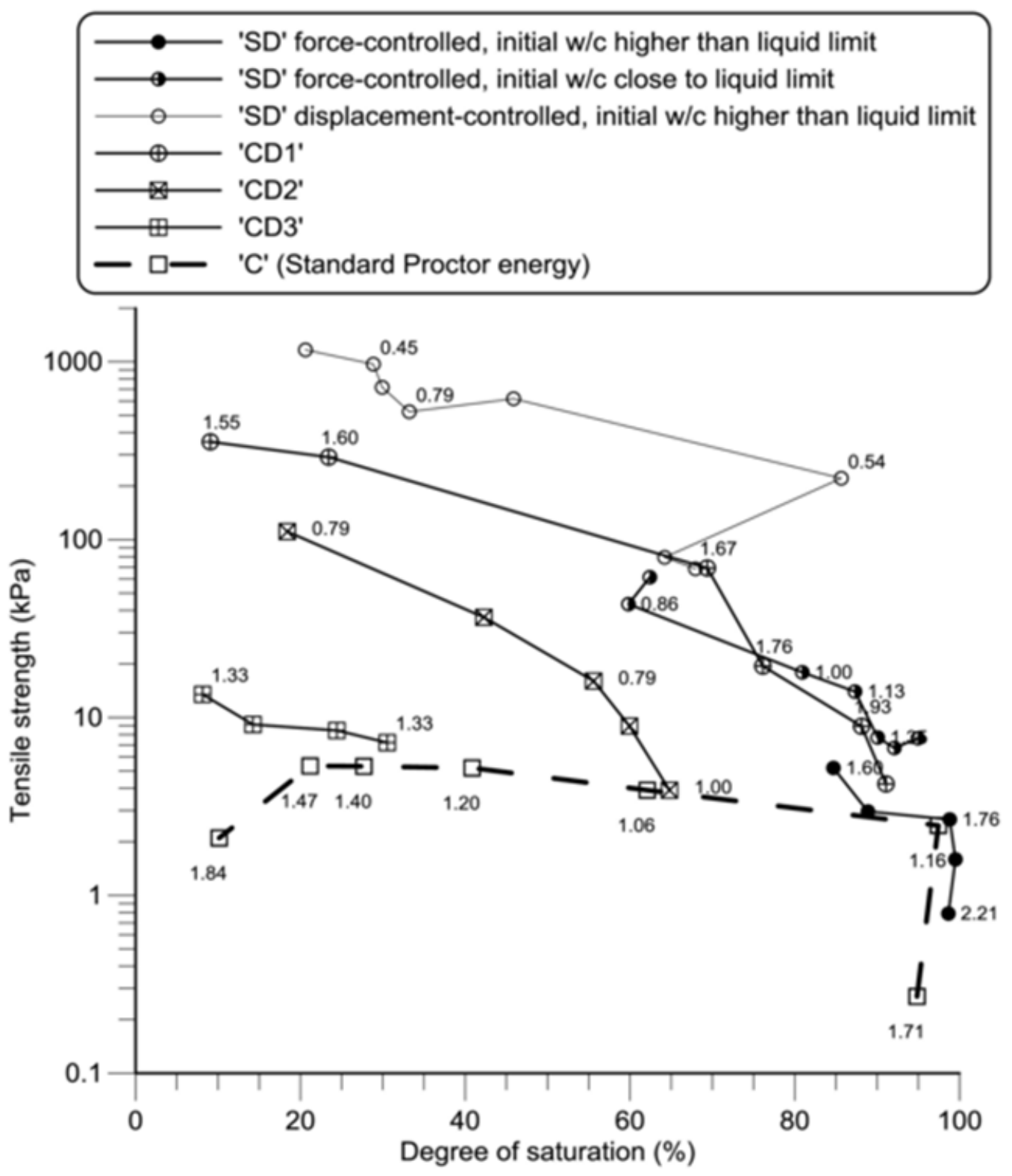

Fig. 11 Tensile strength as a function of degree of saturation for remoulded/dried ('SD'), ascompacted ('C') states and compacted/dried ('CD') paths. Void ratios are indicated by labels.

Figs. 12 and 13 complement the information by plotting tensile strength results in terms of void ratio and suction, respectively (labels in Fig. 12 correspond to water contents). The drying paths ('SD' and 'CD') indicate an increase of tensile strength with decreasing void ratio. The drying paths ('SD' and 'CD') also display a monotonic increase with suction increase. On the contrary, 
as-compacted samples ('C') present a maximum tensile strength at suctions between $5 \mathrm{MPa}$ and $17 \mathrm{MPa}$, and then reduce upon increasing suctions.
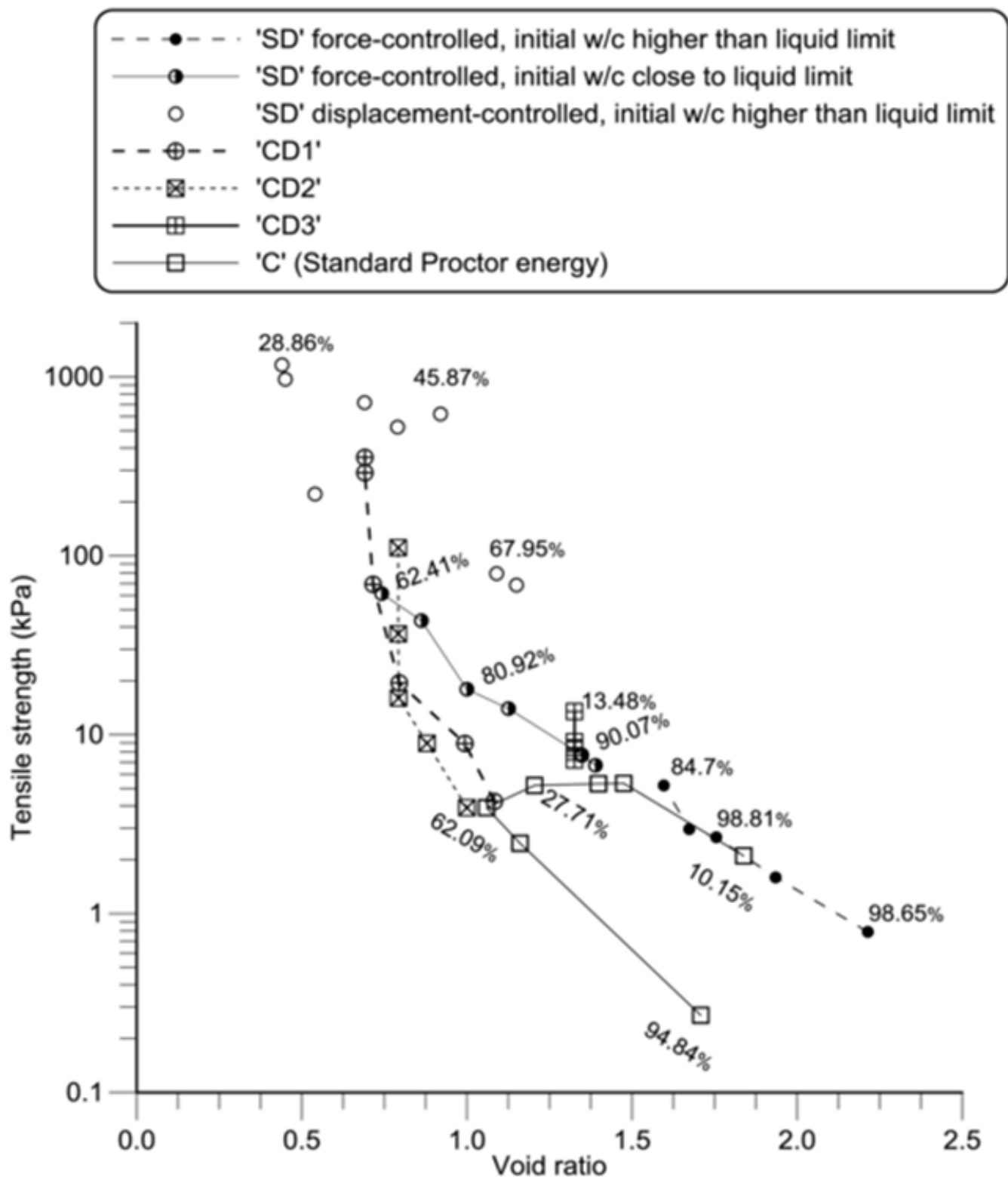

Fig. 12 Tensile strength as a function of void ratio for remoulded/dried ('SD'), as-compacted ('C') states and compacted/dried ('CD') paths. 


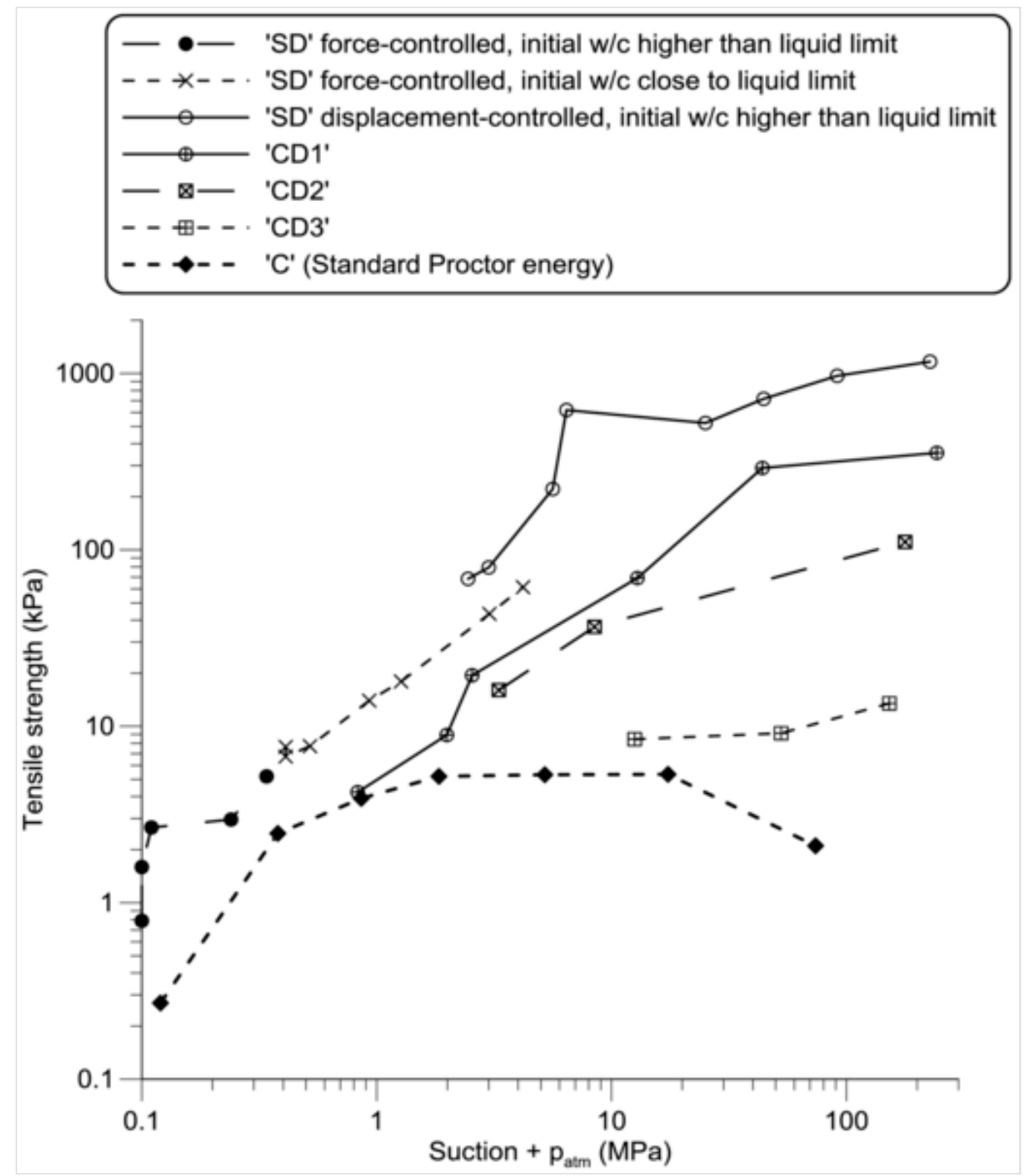

Fig. 13 Tensile strength as a function of suction for remoulded/dried ('SD'), as-compacted ('C') states and compacted/dried ('CD') paths.

\section{Modelling microstructure and water availability on tensile strength}

The previous results have highlighted the important differences observed in tensile strength between compacted and dried states. As remarked in the introductory section of microstructure, these differences are clearly associated with the different pore size distributions attained on compaction and drying, and to the different ways in which suction is held and water stored (inside aggregates or between aggregates). The different storage mechanisms can be separated by defining a microstructural degree of saturation $S_{r}{ }^{m}$ (water adsorbed inside aggregates), and a macrostructural degree of saturation $S_{r}{ }^{M}$ (capillary water between aggregates). Following Romero 
et al. (2014), in which a constant void ratio at the microstructural scale (inside aggregates) $e_{m}^{*}$ is considered below the shrinkage limit (see also Fig. 3), the following expression results

$$
S_{r}^{m}=\frac{e_{w}}{e_{m}^{*}} \leq 1
$$

For $S_{r}{ }^{M}$, the proposal of Della Vecchia et al. (2013) and Romero (2013) is used, in which a smoothing function is incorporated according to the proposal of Alonso et al. (2010)

$$
S_{r}^{M}=\frac{e_{w}-e_{m}^{*}}{e-e_{m}^{*}}+\frac{1}{n_{s}} \ln \left[1+\exp \left(-n_{s} \frac{e_{w}-e_{m}^{*}}{e-e_{m}^{*}}\right)\right]
$$

where $n_{s}=20$ is a model parameter that defines the degree of smoothing around point $e_{m}^{*}$.

Fig. 14 presents the evolution of both degrees of saturation as a function of suction, together with experimental data on drying. A suction value of approximately $s=5 \mathrm{MPa}$ separates the domains of microstructural and macrostructural suctions (this suction is consistent with the lower limit suggested to indicate the domain in which the water retention response in terms of water content is not affected by void ratio changes). 


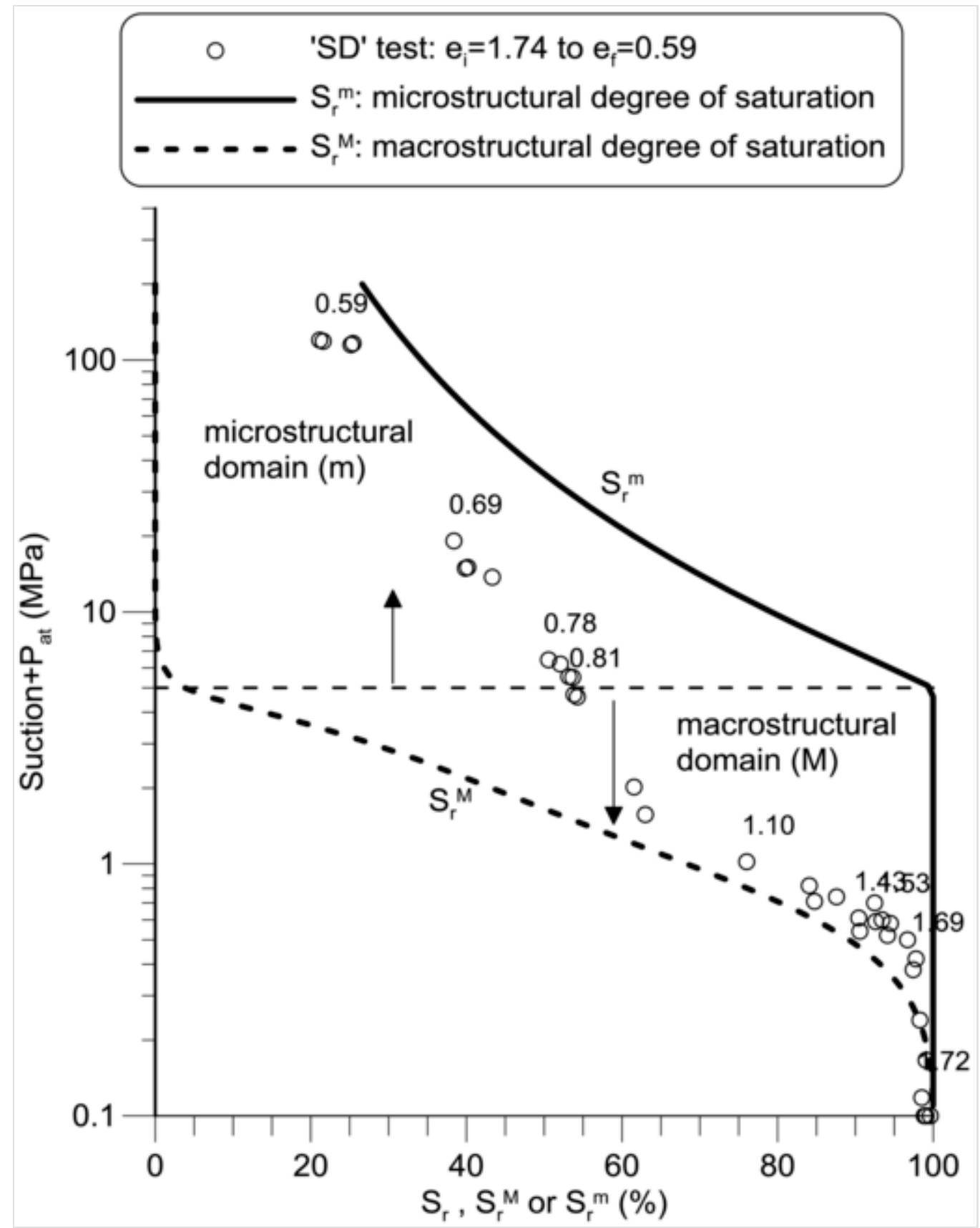

Fig. 14 evolution of both degrees of saturation as a function of suction, together with experimental data on drying.

Considering tensile strength $\sigma_{t}$ to be associated with the capability of the porous media to sustain a given suction $s$ based on the water availability and distribution inside the porous medium (at different structural levels), the following simplified expression is proposed

$\sigma_{t}=\left(a^{m} S_{r}{ }^{m}+a^{M} S_{r}{ }^{M}\right) s+\sigma_{t}^{r e s}$ 
In the above expression, $a^{m}$ is a microstructural parameter linked only to the initial water content of the soil, as will be later discussed. On the contrary, parameter $a^{M}$ linked to the macroscopic degree of saturation at inter-aggregate scale is assumed to keep constant. $\sigma_{t}^{\text {res }}$ is a minimum tensile strength value, which is here considered nil at $s=0$. Minimum tensile strength is expected to depend on the consolidation path (loading/unloading history), but this is not considered in this study.

For compacted soils that do not undergo drying paths (without inducing strong connections between aggregates), $a^{m}$ is assumed to vanish $\left(a^{m}=0\right)$, since tensile strength is assumed to be essentially governed by menisci developing between aggregates (i.e., associated with $S_{r}{ }^{M}$ ). This is the reason why compacted soils develop a maximum tensile strength at intermediate degrees of saturation that reduces to a minimum at $s=0$ or when water is mainly stored inside aggregations (at $S_{r}{ }^{M}=0$ ). The effects of void ratio are indirectly accounted for by its dependence on the water retention properties (refer to Eq. (2)).

Nevertheless, when drying paths are developing after fabrication, then the stiffness of the connections between aggregates appears to drive the tensile strength, and parameter am -that depends on the initial/fabrication water content- displays an important role. The increase in stiffness of these connections (or of the aggregates) on drying is a consequence of two phenomena, namely the reduction of void ratio towards $e_{m}^{*}$ and their desaturation. As a first insight into the problem, only desaturation effects have been considered and the stiffness of the connections have been related to the product of the suction and the degree of saturation at the microstructural level inside aggregates-the product defines an effective suction at microstructural scale-. A similar approach has been followed by Romero et al. (2014) when describing the changes in residual shear strength of active clays upon drying.

Fig. 15 presents tensile strength data of ' $C$ ' and 'SD' tests in terms of water content, together with model simulations at different void ratios ( $e=0.5,1.0,1.5$ and 2.0). Only 'SD' tests with initial water contents higher than the liquid limit have been plotted. The effects of void ratio are more evident at low tensile strength values $\left(\sigma_{t}<100 \mathrm{kPa}\right)$, since its dependence is associated with the water retention properties (void ratio effects on water retention in terms of water content are more important in the low suction domain). 'C' data at constant void ratio have been simulated by considering only the macrostructural degree of saturation $\left(a^{m}=0\right)$, whereas 'SD' data starting from high initial water contents involved the use of both micro and macrostructural information. In this case, for high initial water contents (higher than the liquid limit) a parameter $a^{m}=0.029$ has been considered to fit 'SD' data. This parameter, which is important for the drying paths, is expected to change with the initial water content. As observed, a relatively good agreement between experimental data and simulations is obtained for both ' $\mathrm{C}$ ' and 'SD' samples. 


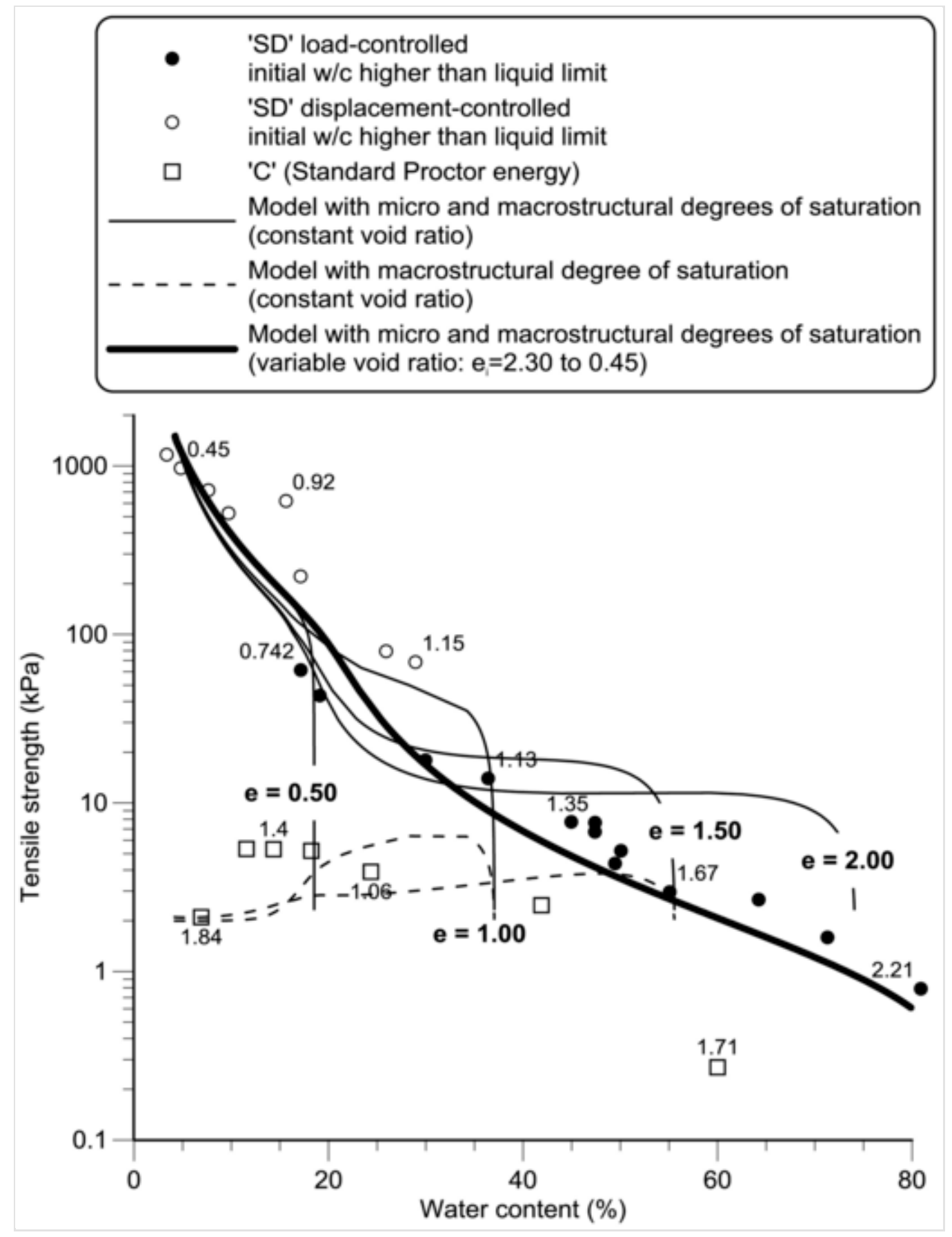

Fig. 15 Tensile strength as a function of water content for remoulded/dried ('SD') and ascompacted (' $C$ ') states. Model simulations at three different void ratios.

Fig. 15 also includes the evolution of the tensile strength upon drying of the 'SD' soil with changing void ratio from $e=2.30$ to 0.46 . To simulate this volume change behaviour, a simple shrinkage model Eq. (8) - linking porosity (or void ratio) to suction- has been used based on experimental information (Trabelsi et al., 2018). 
$n(s)=n_{\text {min }}+\left(n_{\text {max }}-n_{\text {min }}\right)\left(\frac{s_{A E}}{s+s_{A E}}\right) ; \quad e(s)=\frac{n(s)}{1-n(s)}$

where $n_{\min }=0.31$ and $n_{\max }=0.70$ are the minimum and the maximum porosity, respectively. $s_{A E}=0.40 \mathrm{MPa}$ is a parameter related to the air entry value of soil (refer to Fig. 4).

Fig. 16 presents the same information ('C' samples and 'SD' samples starting from very high initial water content) but expressed in terms of degree of saturation. The important effect of void ratio is clearly observed in the model simulations carried out at different void ratios $(e=0.5,1.0$ and 1.5). The capability of the soil to retain water and to keep a high degree of saturation for a given suction increases with the decrease in void ratio (higher air-entry values with decreasing void ratios). The simulation of the tensile strength during drying of a soil undergoing shrinkage from $e=2.3$ to 0.46 is also plotted in the figure. As observed, the path jumps along the different curves at constant void ratio and accurately follows the different experimental values obtained.

Fig. 17 presents tensile strength data of 'SD' and 'CD' tests in terms of water content, together with model simulations during drying of a soil. 'SD' tests with initial water contents higher than or close to the liquid limit have been plotted. As observed in the figure, the evolution of tensile strength on drying is very sensitive to the initial water content (the evolutions tend to follow the same trend on drying, but starting from their respective initial water contents). Test results have been fitted by considering a parameter $a^{m}$ varying with the initial water content (the variation of $a^{m}$ with the initial water content will be later discussed). 


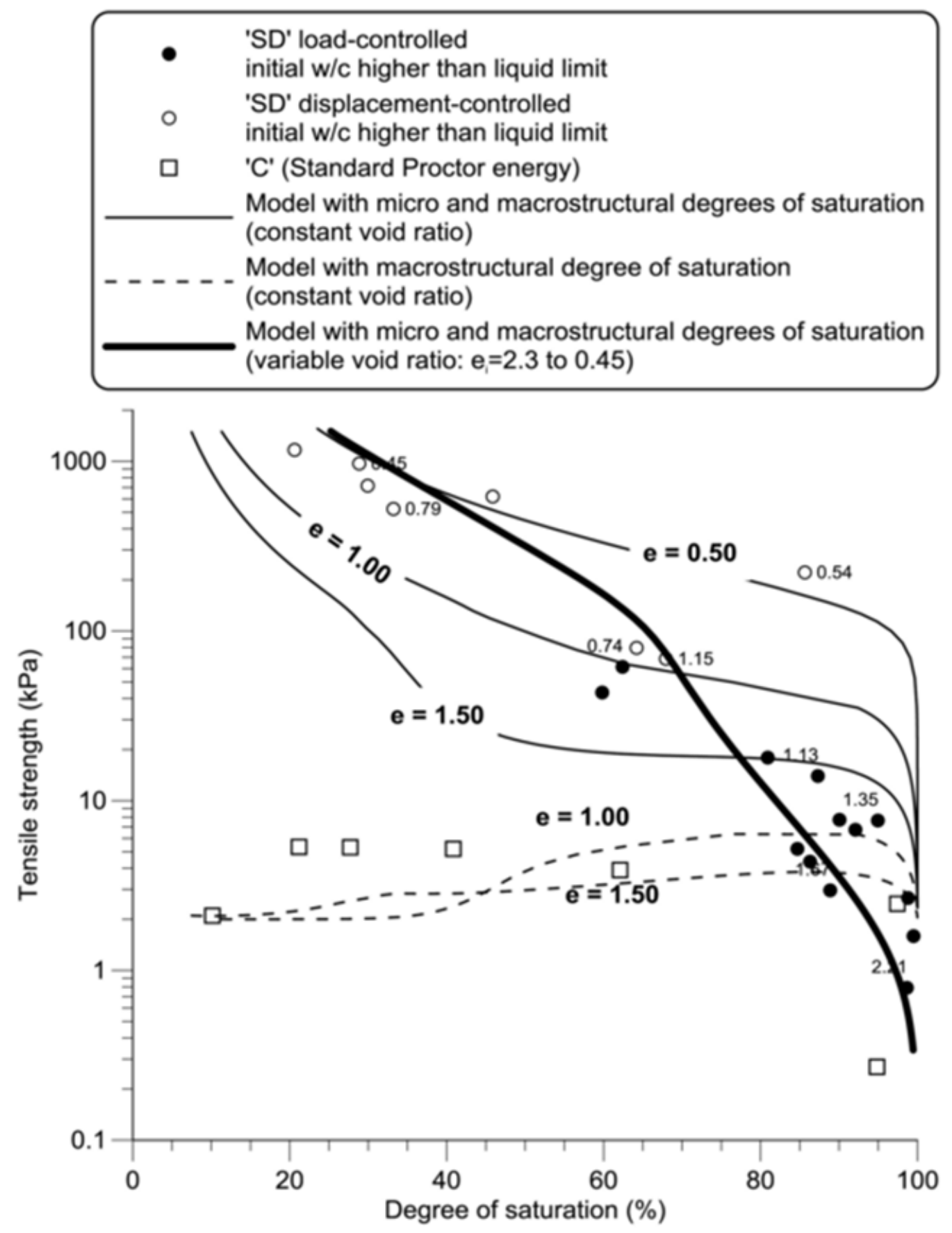

Fig. 16 Tensile strength as a function of degree of saturation for remoulded/dried ('SD') and as-compacted ('C') states. Model simulations at three different void ratios. 


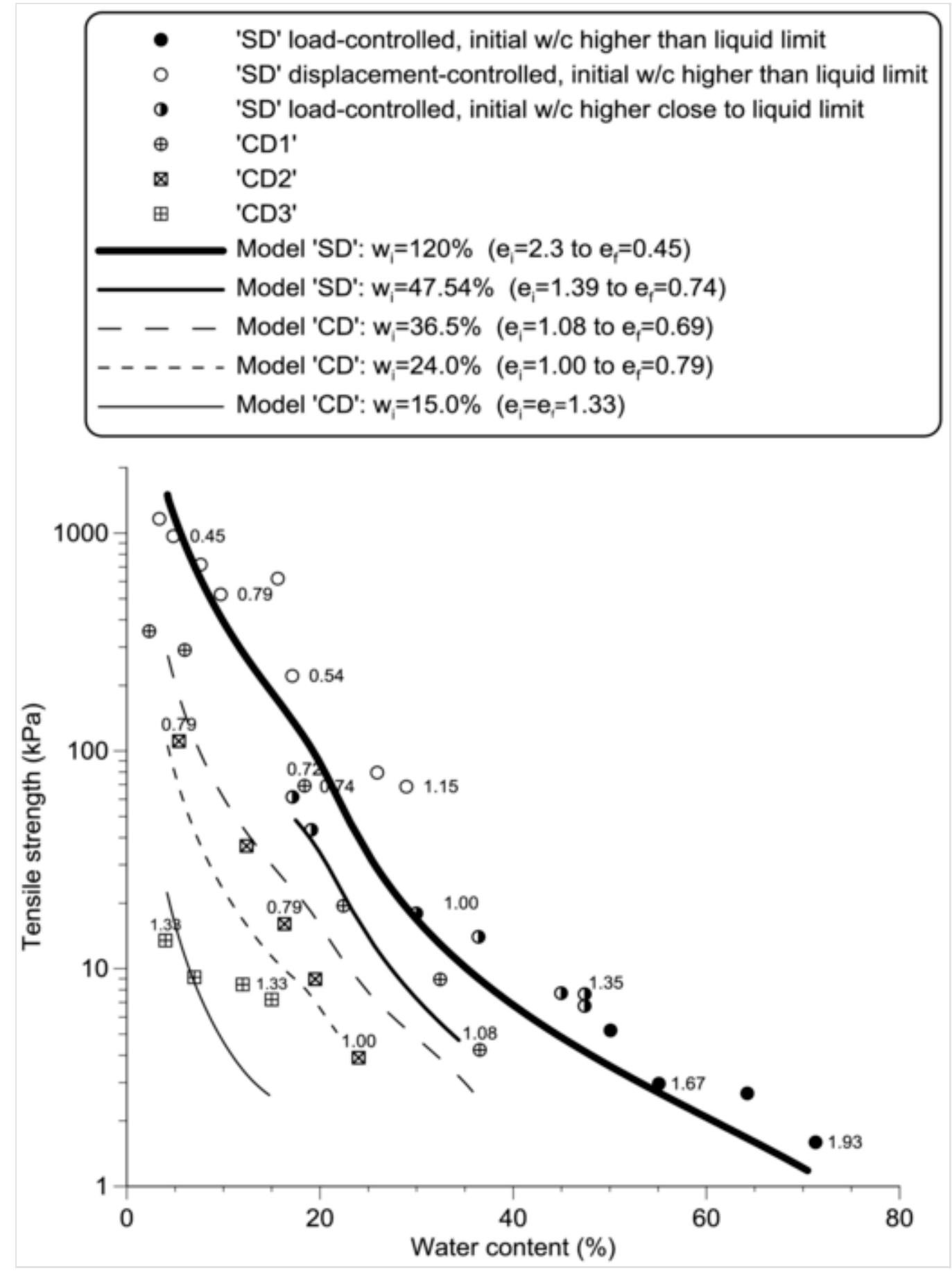

Fig. 17 Tensile strength versus water content for remoulded/dried ('SD') and compacted/dried ('CD') states. Model simulations.

The equivalent tensile strength data in terms of the degree of saturation is presented in Fig. 18 for 'SD' and 'CD' tests. Model simulations for the different drying paths starting at different initial water contents have been also included in the figure. As observed, the initial water content has an important effect in the evolution of the tensile strength along drying paths. 


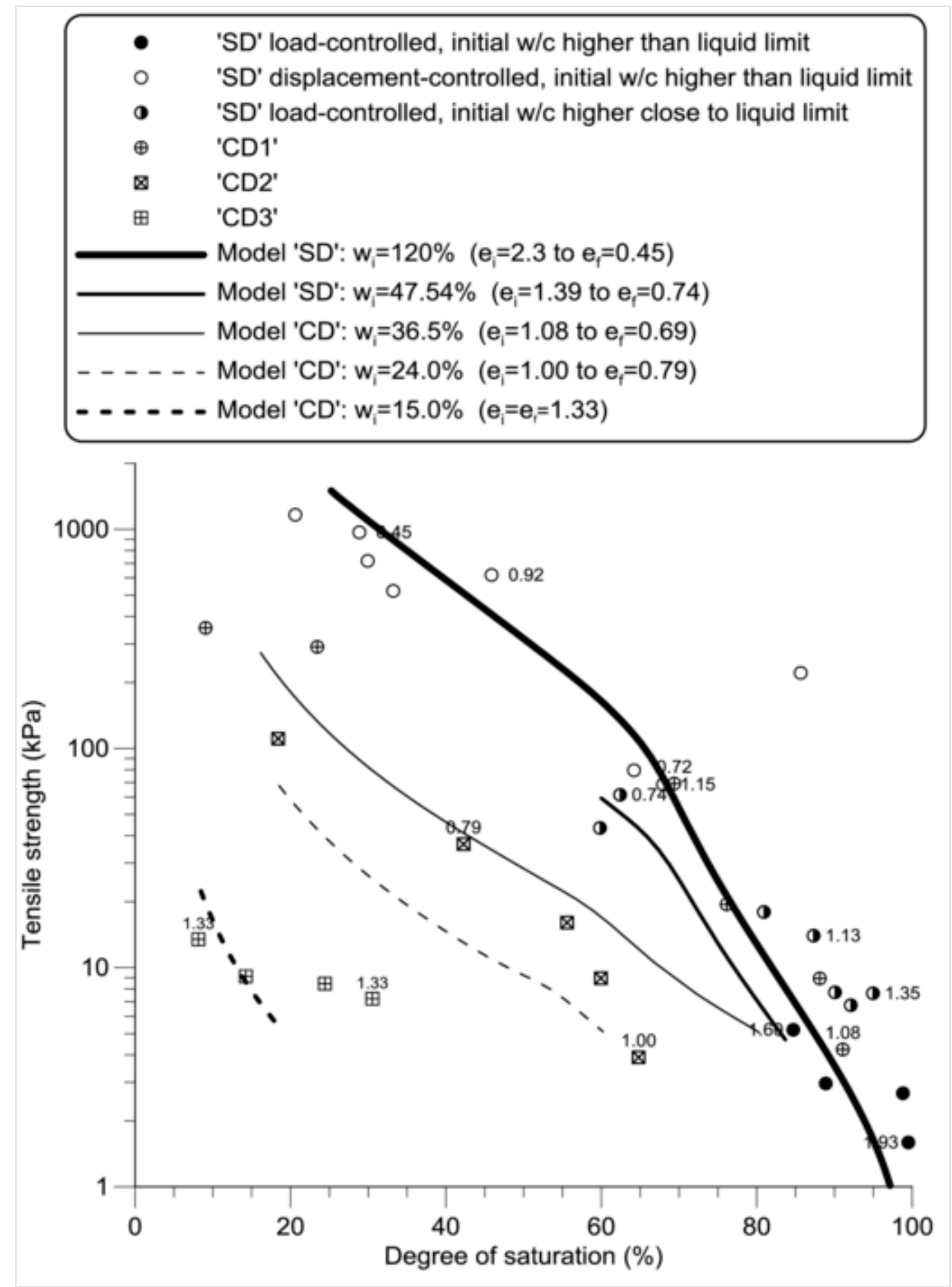

Fig. 18 Tensile strength versus degree of saturation for remoulded/dried ('SD') and compacted/dried ('CD') states. Model simulations.

The fitted $a^{m}$ parameters are plotted as a function of the initial water content in the shrinkage plane shown in Fig. 19. An empirical equation (Eq. (9)), parallel to the shrinkage curve also plotted in the figure, has been proposed to link parameter $a^{m}$ to the initial water content $w_{i}$ (or initial water ratio $e_{w i}$ ). It is assumed that $a^{m}$ vanishes at $w_{i}$ below the shrinkage limit $w_{S L}$ (or $e_{w i}$ below $e_{m}^{*}$ ). 
$a^{m}=\frac{\rho_{s}}{\rho_{w}}\left\langle w_{i}-w_{S L}\right\rangle / 100=\frac{\left\langle e_{w}^{i}-e_{m}^{*}\right\rangle}{100}$

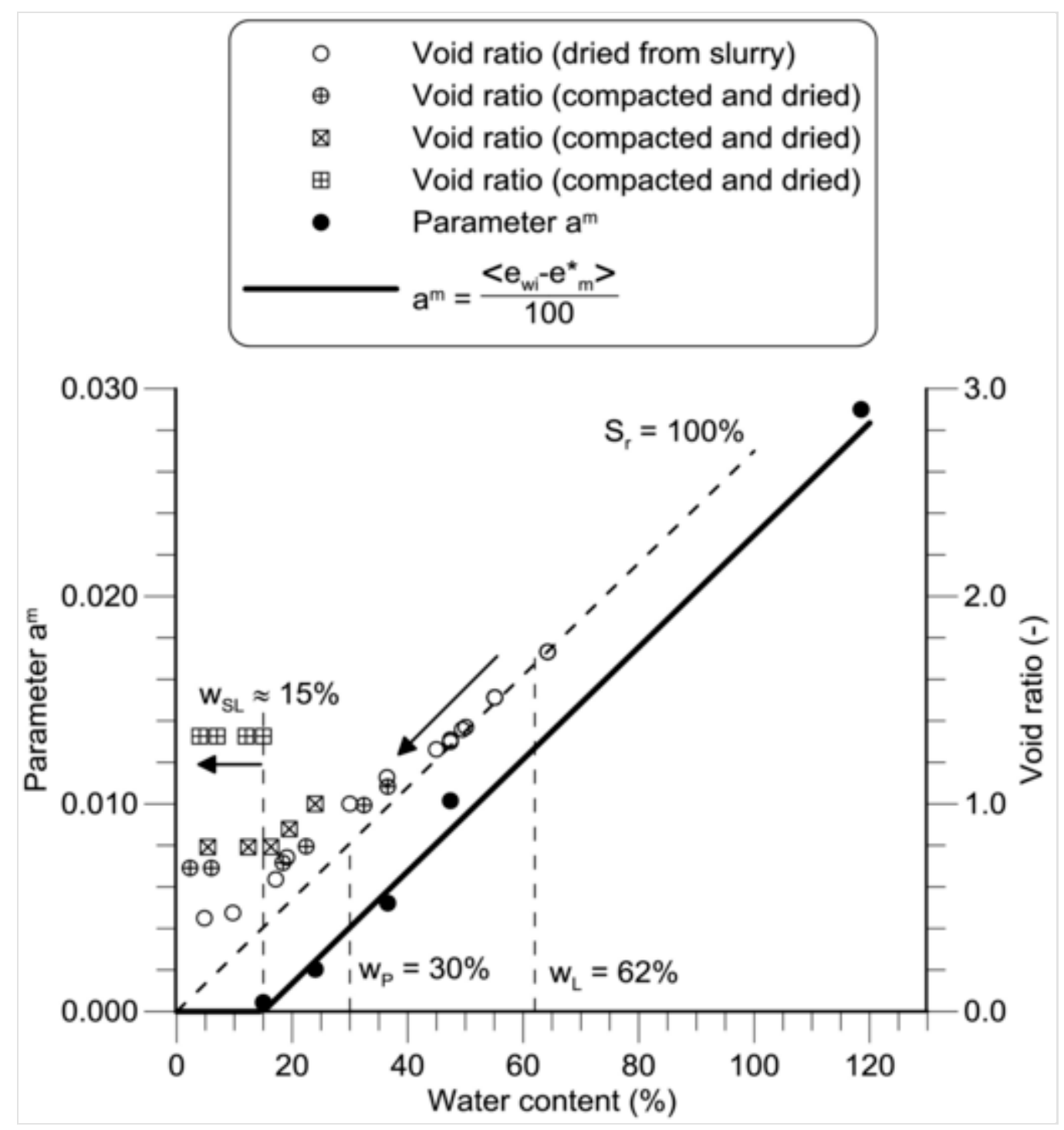

Fig. 19 Variation of microstructural parameter $a^{m}$ with initial water content.

As observed from the previous discussion, Eq. (7) together with a water retention curve (Eq. (2)) that consider micro and macrostructural information appear to adequately reproduce tensile strength results on drying starting from different initial water contents ('SD' and 'CD' paths), as well as on compacted states (' $\mathrm{C}$ ' states). In the case of the drying paths, the tensile strength is clearly affected by the initial water content, as well as by the shrinkage undergone along the path that has influence on the suction developed. Along these drying paths, the suction induced affects 
both the macrostructural water stored between aggregates (macrostructural degree of saturation) and the microstructural water inside aggregates (microstructural degree of saturation), displaying a monotonic increase of the tensile strength on suction increase. In the case of the compacted states, the tensile strength is mainly governed by the macrostructural degree of saturation and the suction developed in the macropores (the tensile strength appears to reach a maximum at an intermediate global degree of saturation and decreases on saturation and at the driest states).

\section{Conclusions}

- The tensile strength of a partially saturated clay, which is a fundamental property controlling crack pattern initiation and propagation, was investigated by direct tensile strength tests and complemented with the study of the water retention properties and microstructural features. A first insight into the problem was done by discussing some of the existing tensile strength results and models presented in the literature.

- A tensile strength apparatus was developed to perform drying paths under controlleddisplacement or controlled-force on an active clay that started from remoulded and compacted states. This way, different microstructural features were initially set on sample fabrication, and a wide range of void ratios and degrees of saturation (from around 10\% to saturation) were explored. Different drying paths and soil states were considered before determining the tensile strength, namely drying paths starting on remoulded states, drying paths after compaction at different initial water contents, and different dynamic compaction states at varying water contents. Samples starting from remoulded states were tested at low controlled-force rate increase, whereas remoulded samples subjected to drying and compacted samples were studied under controlleddisplacement. The latter type of tests allowed detecting a clear peak tensile strength followed by a post-failure regime.

- The samples on drying developed an important shrinkage that affected the water retention and tensile strength properties (the tests indicated that the void ratio and the suction contributed to the tensile strength response). A microstructural model for water retention of active clays was therefore calibrated and used to predict the suction of the samples along the drying paths, which showed the important consequences of void ratio changes. The water retention model also included microstructural features of the sample (microstructural void ratio inside aggregates) that varied along the drying path and affected the air-entry properties of the material at both micro and macrostructural scales.

- A simple model for the tensile strength was proposed based on the consideration that the tensile strength was associated with the capability of the porous medium to sustain a given suction, as 
well as with the water availability at the different microstructural levels (microstructural degree of saturation inside aggregates and macrostructural degrees of saturation between aggregates). For the compacted states, typically showing a multimodal pore size distribution with large macropores, the tensile strength was assumed to be a function of the macrostructural degree of saturation and essentially governed by menisci developing between aggregates. The model applied to compacted states predicted an increase of tensile strength with the decrease of the degree of saturation until reaching a maximum value and then tending to a minimum at null macrostructural degree of saturation. The results and model predictions on compacted states were in good agreement with previous literature results.

- Dry density increase on drying appeared in all cases to dominate the tensile strength response (drying from slurry and drying from compacted states), mainly associated with the increase in the air-entry value. The stiffness of the connections between aggregates appeared to drive the important tensile strength increase (the stiffness was related to the product of the suction and the degree of saturation at the microstructural level inside aggregates). In this case, the model placed more attention on the microstructural degree of saturation and the suction increase when explaining tensile strength results on drying. Good agreements were observed between experimental results on drying and model predictions at decreasing void ratios. The effect of the initial water content was also an important issue when explaining the increase of tensile strength on drying. In fact, the higher the initial water content, the more the tensile strength increase. The latter effect, which was considered by incorporating a microstructural parameter linked to the initial water content, has important practical implications from geotechnical point of view.

\section{References}

Alonso E.E., Pereira J.-M., Vaunat J. and Olivella S, 2010. A microstructurally based effective stress for unsaturated soils. Géotechnique 60 (12), 913-925.

Ammeri A., 2008. Contribution à l'étude expérimentale et numérique du comportement d'un limon sollicité en traction. National Engineering School of Tunis; Tunisia (Ph. D. Thesis dissertation).

Ammeri A., Jamei M., Bouassida M., Ple O., Villard P. and JP Gourc, 2009. Numerical study of bending test on compacted clay by DEM: tensile strength determination. Int. J. Comput. Appl. Technol. 34 (1), 13-22.

Barzegar A.R., Oades J.M., Rengasamy P. and Murry R.S., 1995. Tensile strength of dry, remoulded soils as affected by properties of the clay fraction. Geoderma 65, 93-108. 
Causarano HH., 1993. Factors affecting the tensile strength of soil aggregates. Soil Tillage Res. $28,15-25$.

Della Vecchia G., Jommi C. and Romero E., 2013. A fully coupled elastic-plastic hydromechanical model for compacted soils accounting for clay activity. Int. J. Numer. Anal. Methods Geomech. 37 (5), 503-535, https://doi.org/10.1002/nag.1116.

Della Vecchia G., Dieudonné A.-C. and Jommi C., 2014. Accounting for evolving pore size distribution in water retention models for compacted clays. Int. J. Numer. Anal. Methods Geomech., https://doi.org/10.1002/nag.2326 (Published online).

Divya P.V., Viswanadham B.V.S. and Gourc J.P., 2018. Hydraulic conductivity behaviour of soil blended with geofiber inclusions. Geotext. Geomembr. 46 (2), 121-130.

Faveretti M., 1995. Tensile strength of compacted clays. In: Proceedings of the First International Conference on Unsaturated Soils, vol. 1, 51-56 (Paris, France).

Frydman S., 1964. The applicability of the Brazilian (indirect tension) test to soils. Aust. J. Appl., 335-343.

Hagner T., 2005. Shrinkage Characteristics and Tensile Strength of Cohesive Soils. University of Weimar, Germany (Ph. D.).

Jamei M., Guiras H. and Olivella S., 2015. Analysis of slope movement initiation induced by rainfall using the elastoplastic Barcelona Basic Model. Eur. J. Environ. Civ. Eng., 2015. https://doi.org/10.1080/19648189.2014.996670.

Kim T.H. and Hwang C. 2003. Modeling of tensile strength on moist granular earth material at low water content. Eng. Geol. 69, 233-244.

Kochmanová N. and Tanaka H. 2011. Influence of the soil fabric on the mechanical properties of unsaturated clays. Soils Found. 51 (2), 275-286.

Lakshmikantha M.R., Prat P.C. and Ledesma A., 2012. Experimental evidence of size effect in soil cracking, Can. Geotech. J. 49, 264-284.

Li Y., Ling X., Su L., An L., Li P. and Zhao Y., 2018. Tensile strength of fiber reinforced soil under freeze-thaw condition. Cold Reg. Sci. Technol. 146, 53-59.

Lu N., Wu B. and Tan C. P.C.P.,2005. A Tensile strength apparatus for cohesionless soils, In: Tarantino A. (Eds.), Advanced Experimental Unsaturated Soil Mechanics, pp. 105-110, Trento, Italy.

Lu NN., Wu BB. and Tan C. PC.P., 2007. Tensile strength characteristics of unsaturated sands. J. Geotech. Geoenviron. Eng. 133 (2), 144-154. 
Mikulitsch W. A.W.A. and Gudehus G., 1995. Uniaxial tension, biaxial loading and wetting tests. In: First International Conference on Unsaturated Soils, Paris.

Nahlawi H., Chakrabarti S. and Kodikar J., 2004. A direct tensile strength testing method for unsaturated geomaterials. Geotech. Test. J. 27(4), 356-361.

Nearing M. AM.A., Parker S. CS.C. and Bradford J. MJ.M., 1991. Tensile strength of thirty-three saturated repacked soils. Soil Sci. Soc. Am., P. J. 55, 1546-1551.

Rodriguez R., Sánchez M.J., Ledesma A. and Lloret A., 2007. Experimental and numerical analysis of desiccation of a mining waste. Can. Geotech. J. 44, 2007, 644-658.

Romero EE., 2013. A microstructural insight into compacted clayey soils and their hydraulic properties, Eng. Geol. 165, 2013, 3-19, https://doi.org/10.1016/j.enggeo.2013.05.024.

Romero E. and Simms P. H.P.H., 2008. Microstructure investigation in unsaturated soils: a review with special attention to contribution of mercury intrusion porosimetry and environmental scanning electron microscopy. Geotech. Geol. Eng. 26 (6), 705-727.

Romero E., Della Vecchia G. and Jommi C., 2011. An insight into the water retention properties of compacted clayey soils. Géotechnique $61 \quad$ (4), 313-328. https://doi.org/10.1680/geot.2011.61.4.313.

Romero E., Vaunat J. and Merchán V., 2014. Suction effects on the residual shear strength of clays. J. Geo-Engineering Sci. 2 (1--2), 17-37.

Sanchez M., Gens A., Guimaraes L. and Olivella SS., 2005. A double structure generalized plasticity model for expansion materials. Int. J. Numer. Anal. Methods Geomech. 29, 751787.

Stirling R. A.R.A., 2014. Multiphase Modelling of Desiccation Cracking in Compacted Soil. School of Civil Engineering and Geosciences, Newcastle University; Newcastle, UK, (Phd thesis).

Stumpf L., dos Anjos Leal O., Pauletto E. A.E.A., Pinto L. F. S.L.F.S., Reis D. A.D.A., Pinto M. A. B.M.A.B. and Tuchtenhagen I. K.I.K., 2018. Tensile strength and organic matter fractions in aggregates of a grass-covered mined soil under early stage recovery. Soil Tillage Res. 176, 69-76.

Tamarkar S. B.S.B., Mitachi T. and Toyosawa Y., 2007. Measurement of soil tensile strength and factors affecting its measurements. Soils Foundations 47 (5), 911-918.

Tang C. S.C.S., Pei X. J.X.J., Wang D. Y.D.Y., Shi B. and Li J., 2014. Tensile strength of compacted clayey soil. J. Geotech. Geoenviron. 141 (4), (04014122). 
Trabelsi H., Jamei M., Zenzri H. and Olivella S., 2012. Crack patterns in clayey soils: experiments and modeling, Int. J. Numer. Anal. Methods Geomech. 36(11) 1410-1433 Published on line https://doi.org/10.1002/nag.1060.

Trabelsi H., Hadrich B. and Guiras H., 2018. Evaporation, shrinkage and intrinsic permeability of unsaturated clayey soil: analytical modelling versus experimental data. Arab. J. Geosci. 11, 184, https://doi.org/10.1007/s12517-018-3507-5.

Zeh R.M. and Witt K. J.K.J., 2005. Suction-controlled tensile strength of compacted clay. In: 16th ICSMGE, (Osaka, Japan, September).

Zeh R. M.R.M. and Witt K. J.K.J., 2007. The tensile Strength of Compacted clay as Affected by Suction and Soil Structure, March, Weimar, Germany. pp. 378-386 (Edit Springer Proceeding in Physics). 